\title{
STRUCTURAL ANALYSIS OF RIBBED SLAB
}

\author{
H. M. Soghair *, A. G. Aly *, M. H. Ahmed * and \\ M. A. Farouk ** \\ Civil Engineering Department, Faculty of Engineering, Assiut University \\ ${ }^{*}$ Professor at Civil Eng. Dept., Faculty of Eng., Assiut University, \\ ${ }^{* *}$ Engineer Expert in Ministry of Justice.
}

(Received February 24, 2008 Accepted March 8, 2008)

The traditional analysis methods recommended by design codes such as ACI 318-95 (Building 1995), BS 8110 (structural 1997) and ECP 203 'Egyptian code (2007)' allow the ribbed slab to be analyzed in accordance with the rules for solid slab or as the plain flat slab.

The traditional method doesn't take into consideration a lot of factors in the analysis such as thickness of slab and depth of the ribs.

The ribbed slabs were analyzed in this study using the finite element method through SAP 2000 program. The structure was analyzed as oneunit in two dimensions $x$ and $y$. This study included one way and two way slabs.

This study illustrated the difference in the produced internal forces in the ribs between traditional method and the finite element method. Moreover, this study included the investigation of the factors which aren't taken into account in the traditional method. These factors were the connection between the rib and the supported beam, the effect of solid part on the behavior of rib, the effect of the edge beams on the distribution loads on ribs, the effect of cross ribs, the effect of slab thickness, the effect of the depth of rib, the effect of slab width and the effect of the location of rib.

\section{1- INTRODUCTION}

Ribbed slabs are common types of slabs. The main advantages of using ribbed slabs are permitting a given minimum clear height to be maintained with a reduced overall story height, covering a big horizontal area, simple formwork and reduced own weight. The system exhibits higher stiffness and smaller defections.

Traditional methods of analysis are specified in the current structural codes of most countries for the treatment of regular slab systems. The analysis methods recommended by design codes such as ACI 318-95 (Building 1995), BS 8110 (structural 1997) and ECP 203 'Egyptian code (2007)' allow the ribbed slab to be analyzed in accordance with the rules for solid slab or as the plain flat slab.

In the analysis of ribbed slab as solid slab "traditional', the structural system of the ribs is considered as beams supported on main cross beams which are considered as rigid supports. The supporting beams are assumed to be simple if there is one bay slab and continues supporting beams if there are more then one bay. On this principle which is mentioned previously the internal forces "S.F and B.M" are determined. 
As recommended in this method, solid parts have to be used at the connection of the ribs with the supported beam. These solid parts resist the internal forces which are higher than the loading capacity of the ribs without any effect on the internal forces.

Also, in this method The Egyptian code recommends in addition to the solid part, cross ribs "one to three ribs " in one way ribbed slab when the length of these slabs are greater than $5 \mathrm{~m}$ to decrease the deflection of slab.

The ribbed slab was analyzed exactly by finite element theory through SAP 2000 program. The model provides the actual behavior for ribbed slab by analyzing the structure as one-unite in two dimensions. In this method the structure is divided to frame elements and shell elements. Stiffens matrix for these elements are determined. This method takes into consideration the deformations happened for all elements such as vertical displacements and rotations in the two directions $\boldsymbol{x}, \boldsymbol{y}$, and finding the internal forces produced in these elements exactly. This study is concerned specifically with the analysis of ribbed slab in elastic stage.

\section{2-NUMERICAL STUDY}

\subsection{Comparison between the Two Methods 'Traditional and Exact'}

One way ribbed slab as a model is analyzed by the two methods "traditional and the finite element method ". The Slab was $6 * 10 \mathrm{~m}$ simply supported on four sides and subjected to uniform load $1 \mathrm{t} / \mathrm{m}^{2}$ and as shown in Fig. (1).

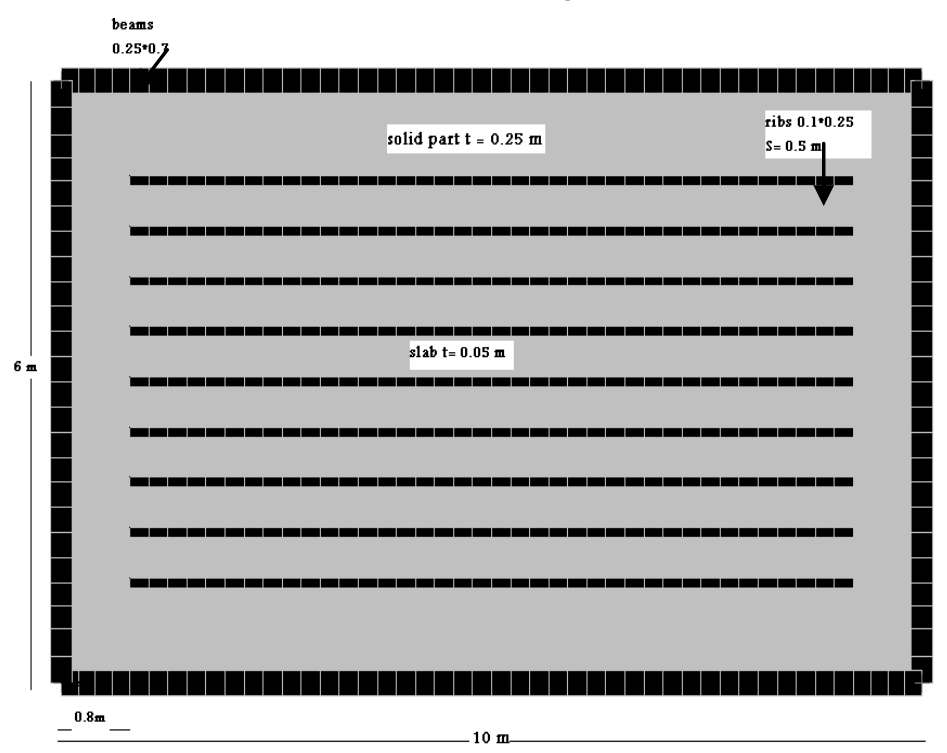

Fig. (1) geometry for one way ribbed slab

The load on each rib equals $0.5 \mathrm{t} / \mathrm{m}$

The shear force and the bending moment are

$$
S . F=\frac{w l}{2}=\frac{0.5 * 8.4}{2}=2.1 t \ldots \ldots .
$$




$$
\begin{aligned}
& B . M_{1}=R x-\frac{w x^{2}}{2}=2.5 * 0.8-\frac{0.5 *(0.8)^{2}}{2}=1.84 m . t \ldots . \\
& B . M_{2}=\frac{w l^{2}}{8}=\frac{0.5}{8} *(10)^{2}=6.25 \text { m.t } \ldots . .
\end{aligned}
$$

Where; - $\quad /=$ the length of rib, $x_{0}=$ width of solid part

$\mathrm{R}=$ the reaction at the end of the rib.

$B . M_{1}$ : B.M at the contact between rib and solid part

B. $M_{2}$ : B.M in the middle of rib

S.F.D and B.M.D for the middle rib by the traditional method are as shown in Fig. (2)
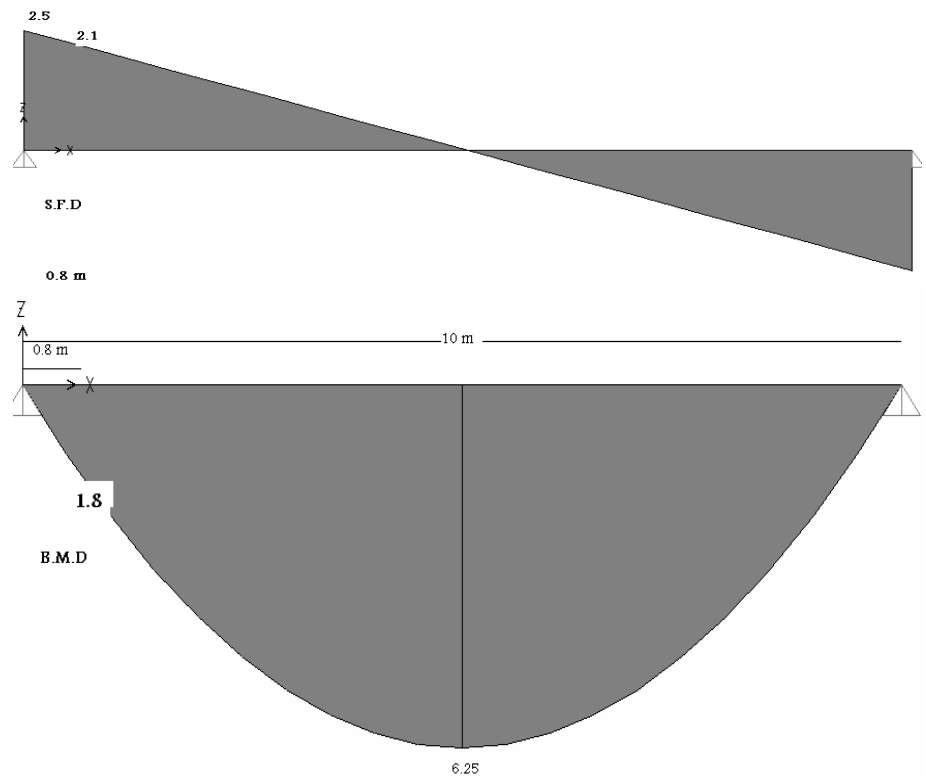

Fig. (2) S.F.D and B.M.D for the rib

S.F.D and B.M.D for the middle rib by the finite element method are as shown in Fig. (3).
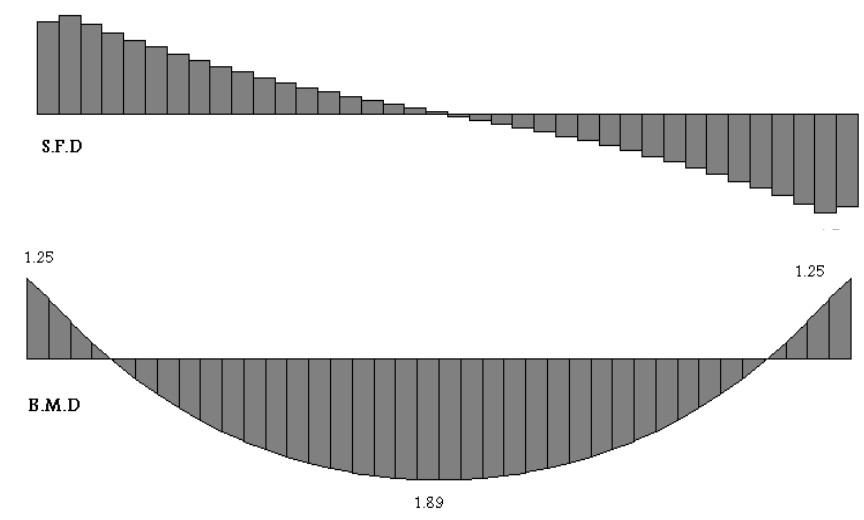

Fig. (3) S.F.D and B.M.D for the rib 
The S.F and B.M for the middle rib in Figs. (2) and (3) show a great difference in the internal forces which are produced by the two methods "traditional method" and "exact method".

The value of S.F produced in the rib in exact method is $71 \%$ the value of S.F in the traditional method. Also the B.M in the middle of the rib in exact method is $30 \%$ the B.M in the traditional method.

Also, in the exact method, the effective load on the rib which causes the moments $\left(B . M_{1}, B . M_{2}\right)$, is

$$
w_{e q}=8\left(\frac{M_{1}+M_{2}}{l^{2}}\right) \ldots \ldots .
$$

In the previous example, it was found that the equivalent load equals $0.35 \mathrm{t} / \mathrm{m}$, this means $70 \%$ of the total load $0.5 \mathrm{t} / \mathrm{m}^{\prime}$ " is transferred by the rib and $30 \%$ is transferred by slab. But in the traditional method a $100 \%$ of the load transfers by the rib. As well as B.M at the connecting zone of the rib with the solid part is positive in the traditional method. The B.M is negative at this connecting zone in the exact method. This moment is very important to be taken in design.

\subsection{Parameters Analysis}

The ribbed slab is analyzed exactly by finite element theory through SAP 2000 program, taking into consideration the following factors;--.

- The connection between the rib and the supported beam.

- The effect of solid part on the behavior of rib.

- The effect of the edge beams on the distribution loads on ribs.

- The effect of cross ribs.

- The effect of slab thickness

- The effect of the depth of rib.

- The effect of slab width.

- $\quad$ The effect of the location of the rib.

Ninety nine slabs were analyzed to study these factors. The slabs were simply supported from each side on beams with section $0.25^{*} 0.7 \mathrm{~m}$. The slabs had constant length equals to $10 \mathrm{~m}$ and variable width and subjected to uniform load equals to 1 $\mathrm{t} / \mathrm{m}^{2}$. These slabs were one way and two ways and the distance between ribs was constant and equals to $0.5 \mathrm{~m}$.

\subsubsection{The Connection between Ribs and the Supported Beam.}

Ribbed slabs of dimensions $\left(6^{*} 10,8 * 10\right.$ and $\left.10^{*} 10\right)$ were analyzed to indicate the effect of connection between ribs and supported beams on B.M in the middle rib. These slabs were one way and the ribs were supported directly on the beams without solid part. Each rib had section $0.1 * 0.25 \mathrm{~m}$ and slab thickness was equal to $0.05 \mathrm{~m}$. The model is as shown in (Fig. 4). 
beams $0.7 \bullet 0.25$

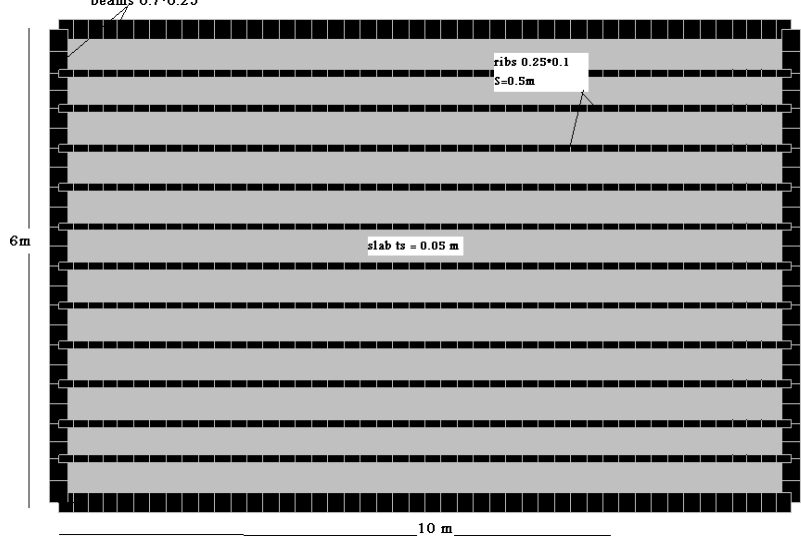

Fig. (4) model of one way ribbed slab without solid part

The B.M.D for the middle rib of slabs by traditional method is as shown in Fig. (5).

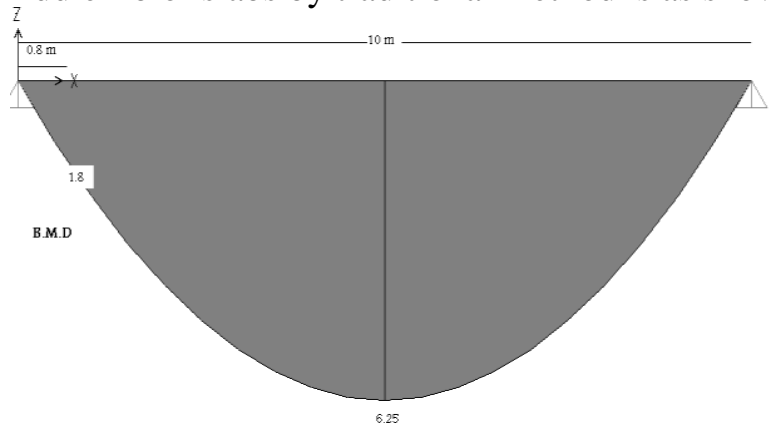

Fig. (5) B.M.D of middle rib by traditional method for all slabs

The B.M.Ds for the middle rib of slabs $(6 * 10,8 * 10$ and $10 * 10)$ by exact method are as ${ }_{21}^{2.1}$ shown in Figs. (6.a, b and c).

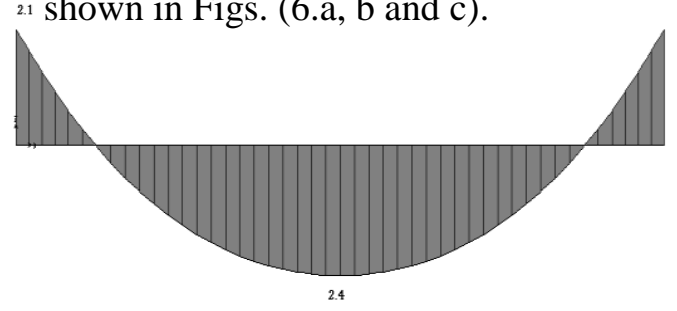

(a) B.M.D for slab $6 * 10$

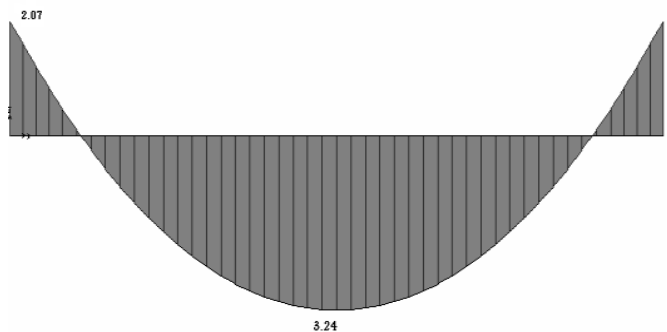

(b) B.M.D for slab $8 * 10$

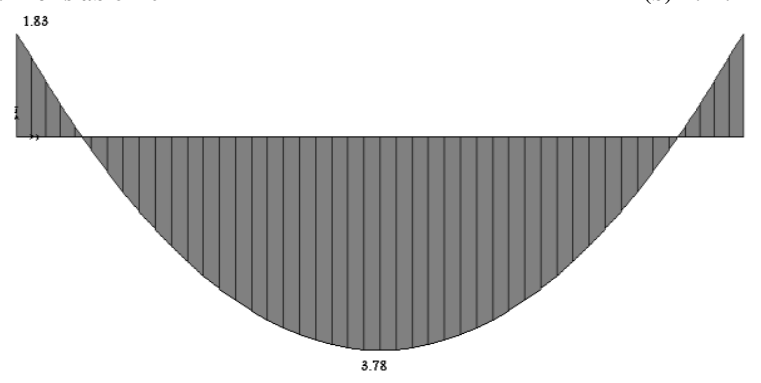

(c) B.M.D for slab 10*10

Fig. (6) B.M.D for the middle rib 
Comparison between Figs. (5) and (6) shows a great difference in the moments for the middle rib between the two methods 'traditional and exact'. The moment produced at the end of the rib by traditional method equals to zero for all slabs. The connection between rib and supported beam is rigid and produces negative moments at the ends of the rib. These moments decrease the positive moment in middle of the rib and transfer to the beam as torsion moments.

Also, the negative moments produced at the ends of the rib decrease when the width of slab increases from $6 \mathrm{~m}$ to $10 \mathrm{~m}$. When the width of slab increases, the span of supported beam increases and its rigidity and the producing negative moments are decreased.

\subsubsection{Effect of Solid Part}

The same ribbed slabs of $\left(6 * 10,8^{*} 10\right.$ and $\left.10^{*} 10\right)$ with and without solid part were analyzed by the exact method. These slabs had ribs in one direction. Each rib had section $0.25^{*} 0.1 \mathrm{~m}$ and thickness of slab $0.05 \mathrm{~m}$. This analysis was divided into two parts:-

The first part: - the effect of solid part on the perpendicular direction of rib. In this part, three cases were analyzed as follows:-

Case I: - width of solid part = zero 'without solid part"

Case II: - width of solid part $=0.04 \mathrm{~L}=40 \mathrm{~cm}$ where " $L$ " length of slab $=10 \mathrm{~m}$

Case III: - width of solid part $=0.08 \mathrm{~L}=80 \mathrm{~cm}$

The model is as shown in Fig. (7).

The second part: - the effect of solid part in both directions, on parallel direction of ribs and the perpendicular one. In this part, two cases were analyzed. Case I: - width of solid part in the parallel direction of the ribs = zero 'without solid part". Case II: -width of solid part in the parallel direction of the ribs $=50 \mathrm{~cm}$. in the two cases width of solid part in the perpendicular direction of ribs $=80 \mathrm{~cm}$ and the thickness of solid part is the same depth as the ribs. The model is as shown in Fig. (8).

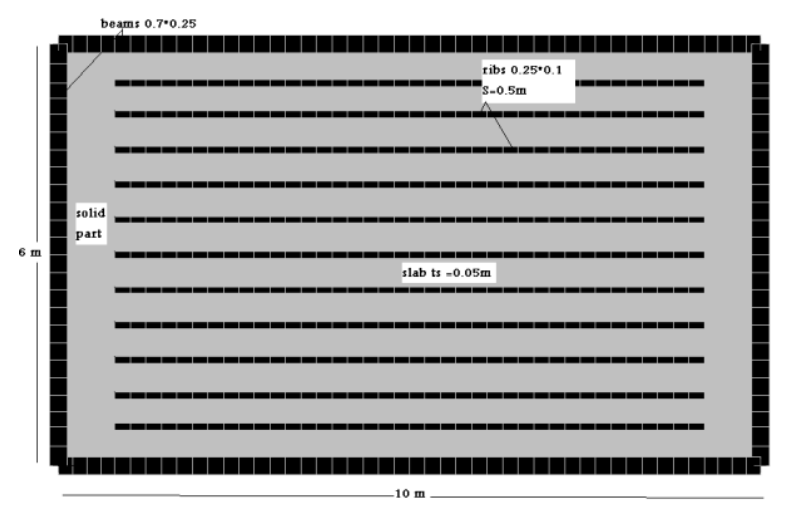

Fig. (7) Solid part on the perpendicular direction of ribs. 


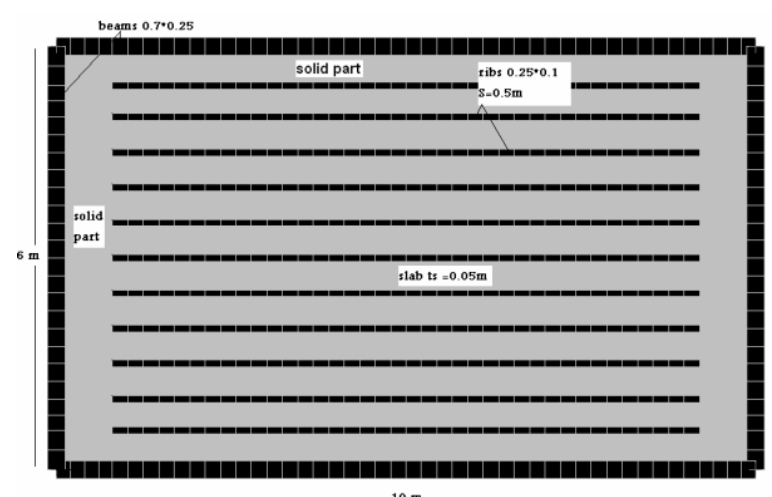

Fig. (8) solid part on the parallel direction of the ribs and the perpendicular direction

\section{A) Solid part on perpendicular direction to rib}

B.M.s of rib for slabs of $6 * 10,8 * 10$ and $10 * 10$ are shown in Table (1).

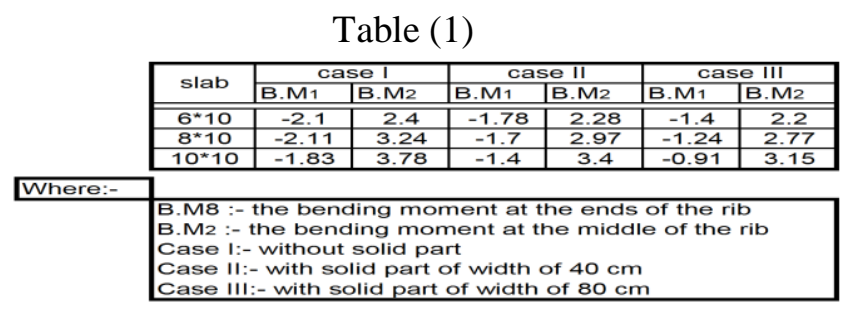

The existence of solid part on the perpendicular direction of the ribs decreases the values of negative and positive B.M produced in the rib.

The percentage of the positive and negative B.M in case of slabs without solid part to their values of slabs with solid part of widths $0.4 \mathrm{~m}$ and $0.8 \mathrm{~m}$ for studied slabs $(6 * 10,8 * 10$ and $10 * 10)$ are tabled as follows :-

Table (2)

\begin{tabular}{|c|c|c|c|c|}
\hline slab & $\begin{array}{l}\text { positive B.M with S.P } 0.4 \mathrm{~m} \\
\text { positive B.M without S.P }\end{array}$ & $\frac{\text { negative B.M with S.P } 0.4 \mathrm{~m}}{\text { negative B.M without S.P }}$ & $\begin{array}{l}\text { positive B.M with S.P } 0.8 \mathrm{~m} \\
\text { positive B.M without S.P }\end{array}$ & $\begin{array}{l}\text { negative B.M with S.P } 0.8 \mathrm{~m} \\
\text { negative B.M without S.P }\end{array}$ \\
\hline $6 * 10$ & $95 \%$ & $84 \%$ & $91 \%$ & $66 \%$ \\
\hline $8 * 10$ & $91 \%$ & $80 \%$ & $85 \%$ & $58 \%$ \\
\hline $10 * 10$ & $90 \%$ & $76 \%$ & $83 \%$ & $50 \%$ \\
\hline
\end{tabular}

Also, The percentage of the values of negative and positive B.M in cases of slabs without solid part to those of with width of solid part $40 \mathrm{~cm}$ and width of solid part $80 \mathrm{~cm}$ for slabs $6 * 10$ and $8 * 10$ to their values for slab $10 * 10$ are as shown in Table (3) ;-

Table (3)

\begin{tabular}{|c|c|c|c|c|}
\hline solid part & $\frac{\text { positive B.M for slab } 6^{*} 10}{\text { positive B.M for slab } 10^{*} 10}$ & $\frac{\text { negative B.M for slab } 6^{*} 10}{\text { negative B.M for slab } 10^{* 10}}$ & $\begin{array}{l}\text { positive B.M for slab } 8^{*} 10 \\
\text { positive B.M for slab } 10^{*} 10\end{array}$ & $\frac{\text { negative B.M for slab } 8^{* 10}}{\text { negative B.M for slab } 10^{*} 10}$ \\
\hline without S.P & $63 \%$ & $114 \%$ & $85 \%$ & $114 \%$ \\
\hline with S.P $40 \mathrm{~cm}$ & $67 \%$ & $127 \%$ & $87 \%$ & $121 \%$ \\
\hline with S.p 80cm & $70 \%$ & $154 \%$ & $88 \%$ & $136 \%$ \\
\hline
\end{tabular}




\section{B) Solid parts on parallel direction of rib and the perpendicular one.}

The B.Ms of rib for slabs of $6 * 10,8 * 10$ and $10 * 10$ are shown in Table 4.

Table (4)

\begin{tabular}{|c|c|c|c|c|}
\hline \multirow{2}{*}{ slab } & \multicolumn{2}{|c|}{ case I } & \multicolumn{2}{c|}{ case II } \\
\cline { 2 - 5 } & B.M1 & B.M2 & B.M1 & B.M2 \\
\hline \hline $6^{*} 10$ & -1.4 & 2.2 & -1.25 & 1.89 \\
\hline $8^{*} 10$ & -1.24 & 2.77 & -1.31 & 2.55 \\
\hline $10^{*} 10$ & -0.91 & 3.15 & -1.05 & 3 \\
\hline
\end{tabular}

\begin{tabular}{l|l|}
\hline Where:- & \\
B.M1 :- the bending moment at the ends of the rib \\
B.M2 :- the bending moment at the middle of the rib \\
Case I:- without solid part \\
Case II:- with solid part of width of $50 \mathrm{~cm}$
\end{tabular}

The existence of solid parts on the parallel direction of the ribs decreases the positive B.M for all studied slabs. The positive B.M produced in the rib with solid part were $86 \%, 92 \%$ and $95 \%$ the positive B.M of case of without solid part for slabs $6 * 10$, $8 * 10$ and $10 * 10$ respectively. But the values of negative B.M of case with solid part were $89 \%, 106 \%$ and $115 \%$ the negative B.M of case without solid part for slabs $6 * 10$, $8 * 10$ and $10 * 10$ respectively.

Also, The percentage of the values of negative and positive B.M in cases of slabs with and without solid part for slabs $6 * 10$ and $8 * 10$ to their values for slab $10 * 10$ are tabled as follows :-

Table (5)

\begin{tabular}{|l|c|c|c|c|}
\hline solid part & $\begin{array}{c}\text { positive B.M for slab } 6^{* 10} \\
\text { positive B.M for slab 10*10 }\end{array}$ & $\begin{array}{c}\frac{\text { negative B.M for slab 6*10 }}{\text { negative B.M for slab 10*10 }} \\
\text { pesitive B.M for slab 8*10 }\end{array}$ & $\begin{array}{c}\frac{\text { negative B.M for slab 8*10 }}{\text { positive B.M for slab 10*10 }} \\
\text { negative B.M for slab 10*10 }\end{array}$ \\
\hline \hline with S.P & $63 \%$ & $119 \%$ & $85 \%$ & $124 \%$ \\
\hline without S.P & $70 \%$ & $154 \%$ & $88 \%$ & $136 \%$ \\
\hline
\end{tabular}

\subsubsection{The effect of edge beam}

Slabs of dimensions of $\left(6^{*} 10,8^{*} 10\right.$ and $\left.10^{*} 10\right)$ with and without edge beam were analyzed to indicate the effect of the edge beams on the behavior of the ribs "middle rib and edge rib'. These slabs had ribs in one direction and supported directly on the beams and the beams were parallel to the ribs. Each rib had section $0.1 * 0.25 \mathrm{~m}$ and the thickness of slab $0.05 \mathrm{~m}$. This section was studied as two cases: - the first case was with edge beams and the second was without edge beam and replaced by rib with the same section of $0.1 * 0.25 \mathrm{~m}$. The model is shown in Fig. (9)

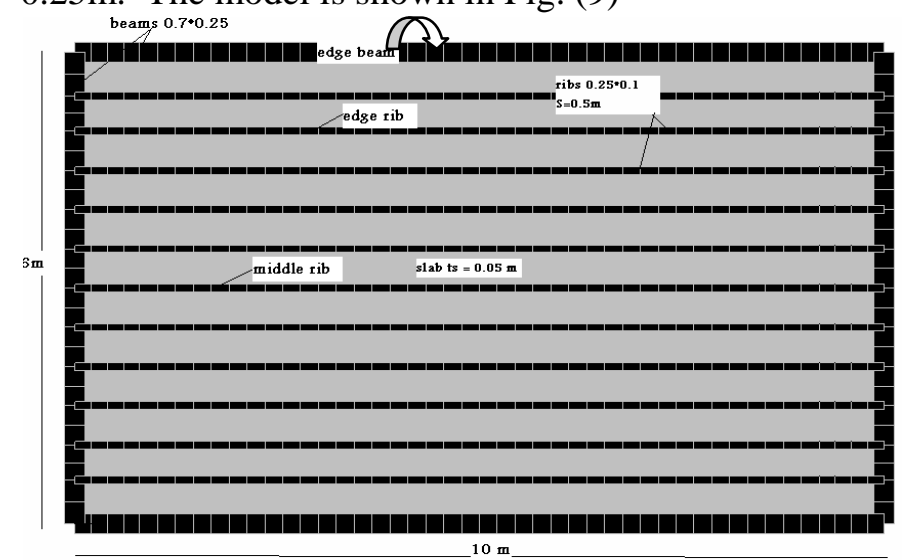

Fig. (9): The effect of edge beam 
The B.Ms of middle rib for slabs $\left(6^{*} 10,8^{*} 10\right.$ and $\left.10^{*} 10\right)$ are shown in Table (6).

Table (6)

\begin{tabular}{|c|c|c|c|c|}
\hline \multirow{2}{*}{ slab } & \multicolumn{2}{|c|}{ case I } & \multicolumn{2}{c|}{ case II } \\
\cline { 2 - 5 } & B.M1 & B.M2 & B.M1 & B.M2 \\
\hline \hline $6 * 10$ & -2.1 & 2.4 & -0.09 & 5.6 \\
\hline $8 * 10$ & -2.11 & 3.24 & -0.11 & 5.73 \\
\hline $10 * 10$ & -1.83 & 3.78 & 0.1 & 5.8 \\
\hline
\end{tabular}

\begin{tabular}{l|l|}
\hline Where:- & \\
& B.M1 :- the bending moment at the ends of the rib \\
B.M2 :- the bending moment at the middle of the rib \\
Case I:- with edge beam \\
Case II:- without edge beam
\end{tabular}

The positive B.M in case I is lower than the positive B.M in case II for all studied slabs. The values of positive B.M of slabs $6 * 10,8^{*} 10$ and $10^{*} 10$ in case I with edge beam are $0.43,0.57$ and 0.65 the values of positive B.M in case II without edge beam respectively . This difference may be because two reasons:-

The first one; in case I, the edge beam parallel to ribs increases the rigidity of slab especially in the perpendicular direction of the ribs and the loads are distributed in two directions. Part of this load is transferred through ribs and the other part is transferred through slab in the perpendicular direction on the rib, and the slabs are as two way. In this case the transferred load through the ribs which is equal to, $w_{e q}=8\left(\frac{M_{1}+M_{2}}{l^{2}}\right)$ is equal to $0.36,0.42,0.44 \mathrm{t} / \mathrm{m}^{`}$ for slabs $6 * 10,8^{*} 10$ and $10^{*} 10$ respectively. But in case II 'without edge beam' the rigidity of slab becomes smaller. This leads to transfer most of the load through the ribs and the load is transferred through ribs in all slabs equally. $w_{e q}=8\left(\frac{M_{1}+M_{2}}{l^{2}}\right)=0.45 \mathrm{t} / \mathrm{m}$ ', and the role of slab in this case in transferring the loads is negligible. This case is completely similar to the solution using the traditional method where the loads are transferred through ribs only.

The second reason is negative moment which is produced at end of the rib at the connection of the rib with supported beam. This moment decreases positive B.M. While in case of slabs without edge beam, the loads transfer completely from slab and ribs to the supported beams which are in the perpendicular direction on the ribs, which leads to increase the displacements of these beams. This causes that the produced negative B.M at the end of rib reaches zero.

The B.M.D of edge ribs in case I with edge beam was different than the produced B.M in the middle rib. While it was in case of without edge beam almost constant compared with the produced B.M in the middle rib for all slabs. The B.Ms of the edge rib for slabs in the two cases for slabs $(6 * 10,8 * 10$ and $10 * 10)$ are shown in Table (7).

Table (7)

\begin{tabular}{|c|c|c|c|c|}
\hline \multirow{2}{*}{ slab } & \multicolumn{2}{|c|}{ case I } & \multicolumn{2}{c|}{ case II } \\
\cline { 2 - 5 } & B.M1 & B.M2 & B.M1 & B.M2 \\
\hline \hline $6^{*} 10$ & -0.6 & 1.3 & 0 & 5.5 \\
\hline $8^{*} 10$ & -0.37 & 1.54 & 0.09 & 5.6 \\
\hline $10^{*} 10$ & -0.85 & 2.22 & 0 & 5.67 \\
\hline
\end{tabular}




\subsubsection{The effect of cross ribs}

Slabs of dimensions $(6 * 10$ and $8 * 10)$ with and without cross ribs were analyzed to study the effect of cross ribs on the internal forces. These slabs had ribs in one direction. Each rib had section $0.1 * 0.2 \mathrm{~m}$ and slab thickness equals to $5 \mathrm{~cm}$. The slabs had solid parts in two directions with width $0.5 \mathrm{~m}$ and $0.8 \mathrm{~m}$ in direction parallel to ribs and perpendicular to ribs respectively. The thickness of solid parts was the same depth of the ribs. Three cases were studied:-

Case I: - slab without cross rib

Case II: - slab with one cross rib

Case III: - slab with three cross ribs

The models of cases II and III are shown in Figs (10 and 11)

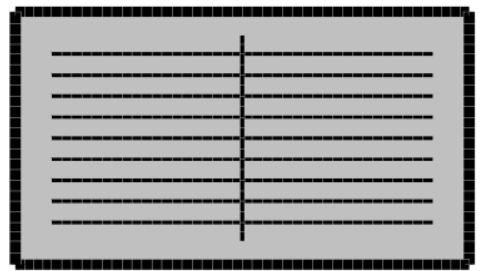

Fig (10) Case II one cross rib

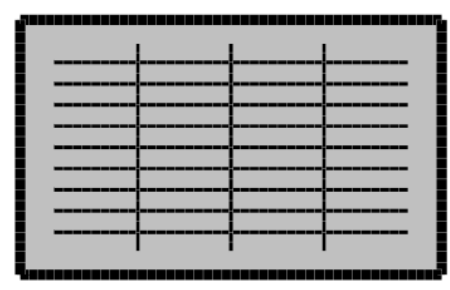

Fig (11) case III three cross ribs

The B.Ms of the different cases for slabs $\left(6^{*} 10\right.$ and $\left.8^{*} 10\right)$ are shown in Tables (8) and (9).

Table (8) B.Ms of the main ribs

\begin{tabular}{|c|c|c|c|c|c|c|}
\hline \multirow{2}{*}{ slab } & \multicolumn{2}{|c|}{ case I } & \multicolumn{2}{c|}{ case II } & \multicolumn{2}{c|}{ case III } \\
\cline { 2 - 7 } & B.M1 & B.M2 & B.M1 & B.M2 & B.M1 & B.M2 \\
\hline \hline $6^{*} 10$ & -1.25 & 1.89 & -0.78 & 1.4 & -0.56 & 1.36 \\
\hline $8^{*} 10$ & -1.31 & 2.55 & -1 & 2.18 & -0.83 & 2 \\
\hline
\end{tabular}

Table (9) B.Ms of the cross ribs

\begin{tabular}{|c|c|c|c|c|c|}
\hline \multirow{2}{*}{ slab } & \multicolumn{2}{c|}{ case II } & \multicolumn{2}{c|}{ case III } \\
\cline { 3 - 6 } \multicolumn{1}{l|}{} & B.M1 & B.M2 & B.M1 & B.M2 \\
\hline \hline $6^{*} 10$ & -1.94 & 2.6 & -1.35 & 2.16 \\
\hline $8^{*} 10$ & -2.63 & 2.84 & -1.95 & 2.5 \\
\hline
\end{tabular}

The produced B.M in the main ribs for slabs using cross ribs was decreased compared with those without cross ribs. The values of negative and positive B.M in cases of slabs with one cross rib and three cross ribs to their values in case of slabs without cross ribs are as in Table (10) :-

Table (10)

\begin{tabular}{|c|c|c|c|c|}
\hline slab & $\frac{\text { positive B.M with one cross rib }}{\text { positive B.M without cross rib }}$ & $\frac{\text { negative B.M with one cross rib }}{\text { negative B.M without cross rib }}$ & $\begin{array}{l}\text { positive B.M with three cross rib } \\
\text { positive B.M without cross rib }\end{array}$ & $\frac{\text { negative B.M with three cross rib }}{\text { negative B.M without cross rib }}$ \\
\hline $6 * 10$ & $74 \%$ & $62 \%$ & $72 \%$ & $45 \%$ \\
\hline $8 * 10$ & $85 \%$ & $76 \%$ & $78 \%$ & $63 \%$ \\
\hline
\end{tabular}

The produced B.M in the cross ribs were great compared with the main ribs and must be taken into consideration. The values of negative and positive B.M in cases 
of with one cross rib and three cross ribs for cross rib to their values of the main rib are as in Table (11) :-

Table (11)

\begin{tabular}{|c|c|c|c|c|}
\hline \multirow{2}{*}{ slab } & \multicolumn{2}{|c|}{ case of one cross rib } & \multicolumn{2}{c|}{ case of three cross ribs } \\
\cline { 2 - 5 } & $\begin{array}{c}\text { positive B.M for cross rib } \\
\text { positive B.M for main rib }\end{array}$ & $\begin{array}{c}\text { negative B.M for cross rib } \\
\text { negative B.M for main rib }\end{array}$ & $\begin{array}{c}\text { positive B.M for cross rib } \\
\text { positive B.M for main rib }\end{array}$ & $\begin{array}{c}\text { negative B.M for cross rib } \\
\text { negative B.M for main rib }\end{array}$ \\
\hline \hline $6 * 10$ & $185 \%$ & $250 \%$ & $158 \%$ & $240 \%$ \\
\hline $8 * 10$ & $130 \%$ & $263 \%$ & $125 \%$ & $235 \%$ \\
\hline
\end{tabular}

Also, the B.M of cross rib decreases with increasing the number of cross ribs. The values of negative and positive B.M for cross rib of case III for slab $6 * 10$ are $70 \%$ and $83 \%$ the values of negative and positive B.M for cross rib of case II. The values of negative and positive B.M for cross rib of case III for slab $8 * 10$ are $74 \%$ and $88 \%$ the values of negative and positive B.M for cross rib of case II.

\subsubsection{The effect of slab thickness}

This section is divided into two parts, the first is concerned with one way ribbed slabs and the second is concerned with two way ribbed slabs.

\section{A) One way ribbed slabs.}

One way slabs of dimensions $(4 * 10,6 * 10,8 * 1010 * 10$ and $12 * 10)$ were analyzed. These slabs had ribs in one direction. Each rib had section of $0.1 * 0.2 \mathrm{~m}$ and the slab thicknesses were $(4,5,8,12,16) \mathrm{cm}$ for each slab. The slabs had solid parts in two directions, direction parallel to ribs and perpendicular to ribs with width $0.5 \mathrm{~m}$ and $0.8 \mathrm{~m}$ respectively. The thickness of solid parts was the same depth of the ribs. The S.Fs and B.Ms for the middle rib of slabs $\left(4 * 10,6 * 10,8 * 10,10^{*} 10\right.$, and $\left.12 * 10\right)$ are tabled as follows:-

Table (12)

\begin{tabular}{|c|c|c|c|c|c|c|}
\hline \multicolumn{7}{|c|}{ summary for the internal force in the middle rib } \\
\hline \multirow{2}{*}{ forces } & \multirow{2}{*}{ SLAB } & \multicolumn{5}{|c|}{ rigidity of slab at depth of ribs $=20 \mathrm{~cm}$} \\
\hline & & $\mathrm{ts}=4 \mathrm{~cm}$ & $\mathrm{ts}=5 \mathrm{~cm}$ & ts $=8 \mathrm{~cm}$ & ts $=12 \mathrm{~cm}$ & $t \mathrm{~s}=16 \mathrm{~cm}$ \\
\hline S.F $(t)$ & \multirow{4}{*}{$4 * 10$} & 0.96 & 0.74 & 0.42 & 0.19 & 0.11 \\
\hline B.M "1" (m.t) & & -0.7 & -0.46 & -0.136 & 0.03 & 0.07 \\
\hline B.M "2" (m.t) & & 0.64 & 0.53 & 0.41 & 0.35 & 0.3 \\
\hline eq. Load (t/m') & & 0.150 & 0.112 & 0.106 & 0.061 & 0.026 \\
\hline S.F $(t)$ & \multirow{4}{*}{$6 * 10$} & 1.54 & 1.3 & 0.7 & 0.24 & 0.15 \\
\hline B.M"1" (m.t) & & -1.46 & -1.11 & -0.38 & 0 & 0.09 \\
\hline B.M "2" (m.t) & & 1.5 & 1.28 & 0.84 & 0.59 & 0.45 \\
\hline eq. Load (t/m') & & 0.336 & 0.271 & 0.138 & 0.067 & 0.041 \\
\hline S.F (t) & \multirow{4}{*}{$8 * 10$} & 1.74 & 1.57 & 0.92 & 0.34 & 0.17 \\
\hline B.M "1" (m.t) & & -1.62 & -1.37 & -0.57 & -0.03 & 0.09 \\
\hline B.M "2" (m.t) & & 2.1 & 1.95 & 1.34 & 0.86 & 0.6 \\
\hline eq. Load (t/m') & & 0.422 & 0.376 & 0.217 & 0.101 & 0.058 \\
\hline S.F (t) & \multirow{4}{*}{$10 * 10$} & 1.77 & 1.65 & 1.04 & 0.35 & 0.2 \\
\hline B.M "1" (m.t) & & -1.44 & -1.29 & -0.6 & -0.03 & 0.08 \\
\hline B.M "2" (m.t) & & 2.52 & 2.4 & 1.8 & 1.12 & 0.71 \\
\hline eq. Load (t/m') & & 0.449 & 0.418 & 0.272 & 0.130 & 0.071 \\
\hline S.F $(t)$ & \multirow{4}{*}{$12 * 10$} & 1.78 & 1.66 & 1.1 & 0.42 & 0.21 \\
\hline B.M "1" (m.t) & & -1.17 & -1.07 & -0.52 & 0 & 0.1 \\
\hline B.M "2" (m.t) & & 2.87 & 2.76 & 2.15 & 1.34 & 0.8 \\
\hline eq. Load $\left(t / m^{\prime}\right)$ & & 0.458 & 0.434 & 0.303 & 0.152 & 0.079 \\
\hline \multicolumn{7}{|l|}{ Notes } \\
\hline \multicolumn{7}{|c|}{$\begin{array}{l}\text { ts ;- the thickness os slab } \\
\text { S.F :- max. Shear force for the rib } \\
\text { B.M "1" :- bending moment for rib at connectting with solid part } \\
\text { B.M "2" :- bending moment at mid of the rib }\end{array}$} \\
\hline \multicolumn{4}{|c|}{ eq. load :- equivalent load for moments } & \multicolumn{3}{|c|}{$=8\left(\frac{M_{1}+M_{2}}{l^{2}}\right)$} \\
\hline
\end{tabular}

The produced shear force and bending moments in the rib decrease as the thickness of slab increases. 
The values of S.F for slabs $(4 * 10,6 * 10,8 * 10,10 * 10$ and $12 * 10)$ with thickness of $16 \mathrm{~cm}$ are $11.5 \%, 9.7 \%, 9.8 \%, 11.3 \%$ and $11.8 \%$ the values of S.F for slabs with thickness of $4 \mathrm{~cm}$ respectively.

The values of positive B.M for slabs $(4 * 10,6 * 10,8 * 10,10 * 10$ and $12 * 10)$ with thickness of $16 \mathrm{~cm}$ are $46.9 \%, 30 \%, 28.6 \%, 28.2 \%$ and $27.9 \%$ the values of B.M for slabs with thickness of $4 \mathrm{~cm}$ respectively.

Also, the values of the equivalent load for slabs $(4 * 10,6 * 10,8 * 10,10 * 10$ and $12 * 10)$ with thickness of $16 \mathrm{~cm}$ are $17.3 \%, 12.2 \%, 13.7 \%, 15.8 \%$ and $17.2 \%$ the values of the equivalent load for slabs with thickness of $16 \mathrm{~cm}$ respectively.

The produced B.M at the connection between rib and solid part changes with the change of slab thickness. The value of this moment is negative for slabs with thickness of $4 \mathrm{~cm}$ then decreases with increasing the thickness until reaches to zero or positive value for slabs with thickness of $16 \mathrm{~cm}$.

\section{B) Two way ribbed slabs.}

Ribbed slabs of dimensions $(6 * 10,8 * 10$ and $10 * 10)$ were analyzed. These slabs had ribs in two directions. Each rib had section $0.1 * 0.2 \mathrm{~m}$ and slab thicknesses were $(4,5$, $8,12,16) \mathrm{cm}$. The slabs hade solid parts in two directions, direction parallel to ribs and perpendicular to ribs with width $0.55 \mathrm{~m}$. The thickness of solid parts is the same depth of the ribs. The S.Fs, B.Ms in the middle rib in each direction for slabs $(6 * 10),(8 * 10)$ and (10*10) are shown in Tables (13) and (14).

Table (13) direction a

\begin{tabular}{|c|c|c|c|c|c|c|}
\hline \multicolumn{7}{|c|}{ summary for the internal force in the middle rib direction a } \\
\hline \multirow{2}{*}{ forces } & \multirow{2}{*}{ SLAB } & \multicolumn{5}{|c|}{ rigidity of slab at depth of ribs $=20 \mathrm{~cm}$} \\
\hline & & ts $=4 \mathrm{~cm}$ & $\mathrm{ts}=5 \mathrm{~cm}$ & $\mathrm{ts}=8 \mathrm{~cm}$ & ts $=12 \mathrm{~cm}$ & $\mathrm{ts}=16 \mathrm{~cm}$ \\
\hline S.F $(t)$ & \multirow{4}{*}{$6 * 10$} & 0.93 & 0.83 & 0.55 & 0.26 & 0.14 \\
\hline B.M "1" (m.t) & & -0.26 & -0.23 & -0.09 & -0.03 & 0.05 \\
\hline B.M "2" (m.t) & & 0.99 & 0.95 & 0.8 & 0.53 & 0.31 \\
\hline eq. Load (t/m') & & 0.416 & 0.393 & 0.296 & 0.186 & 0.087 \\
\hline S.F $(\mathrm{t})$ & \multirow{4}{*}{$8 * 10$} & 1.15 & 1.06 & 0.7 & 0.31 & 0.15 \\
\hline B.M"1" (m.t) & & -0.62 & -0.55 & -0.29 & -0.02 & 0.05 \\
\hline B.M "2" (m.t) & & 1.4 & 1.36 & 1.13 & 0.76 & 0.48 \\
\hline eq. Load (t/m') & & 0.339 & 0.321 & 0.239 & 0.131 & 0.072 \\
\hline$S . F(t)$ & \multirow{4}{*}{$10 * 10$} & 1.29 & 1.19 & 0.8 & 0.35 & 0.17 \\
\hline B.M "1" (m.t) & & -0.88 & -0.79 & -0.43 & -0.06 & 0.06 \\
\hline B.M "2" (m.t) & & 1.72 & 1.67 & 1.41 & 1 & 0.68 \\
\hline eq. Load (t/m') & & 0.262 & 0.248 & 0.186 & 0.107 & 0.063 \\
\hline
\end{tabular}

Table (14) direction b

\begin{tabular}{|c|c|c|c|c|c|c|}
\hline \multicolumn{7}{|c|}{ summary for the internal force in the middle rib direction b } \\
\hline \multirow{2}{*}{ forces } & \multirow{2}{*}{ SLAB } & \multicolumn{5}{|c|}{ rigidity of slab at depth of ribs $=20 \mathrm{~cm}$} \\
\hline & & $\mathrm{ts}=4 \mathrm{~cm}$ & $\mathrm{ts}=5 \mathrm{~cm}$ & ts $=8 \mathrm{~cm}$ & ts $=12 \mathrm{~cm}$ & ts $=16 \mathrm{~cm}$ \\
\hline S.F (t) & \multirow{4}{*}{$6 * 10$} & 0.81 & 0.74 & 0.5 & 0.24 & 0.14 \\
\hline B.M "1" (m.t) & & -0.41 & -0.37 & -0.2 & 0 & 0.06 \\
\hline B.M "2" (m.t) & & 0.7 & 0.68 & 0.63 & 0.54 & 0.44 \\
\hline eq. Load (t/m') & & 0.112 & 0.106 & 0.084 & 0.055 & 0.038 \\
\hline S.F $(\mathrm{t})$ & \multirow{4}{*}{$8 * 10$} & 1.05 & 0.98 & 0.67 & 0.3 & 0.16 \\
\hline B.M "1" (m.t) & & -0.68 & -0.61 & -0.34 & -0.05 & 0.06 \\
\hline B.M "2" (m.t) & & 1.18 & 1.15 & 1.01 & 0.77 & 0.57 \\
\hline eq. Load (t/m') & & 0.188 & 0.178 & 0.136 & 0.083 & 0.052 \\
\hline S.F $(\mathrm{t})$ & \multirow{4}{*}{$10 * 10$} & 1.29 & 1.19 & 0.8 & 0.35 & 0.17 \\
\hline B.M "1" (m.t) & & -0.88 & -0.79 & -0.43 & -0.06 & 0.06 \\
\hline B.M "2" (m.t) & & 1.72 & 1.67 & 1.41 & 1 & 0.68 \\
\hline eq. Load (t/m') & & 0.262 & 0.248 & 0.186 & 0.107 & 0.063 \\
\hline
\end{tabular}

The produced internal forces in the ribs in each direction decrease with the increase of the thickness of slab.

The values of S.F and positive B.M in direction 'a` at thickness $16 \mathrm{~cm}$ of slab 6*10 are $15 \%$ and $31.3 \%$ the values of S.F and B.M at thickness of $4 \mathrm{~cm}$ of slab respectively.

Also, the values of S.F and B.M in direction ' $b$ ' at thickness of $16 \mathrm{~cm}$ of slab are $17.3 \%$ and $62.9 \%$ the values of S.F and B.M at thickness of $4 \mathrm{~cm}$ of slab respectively .

The percentage of the load transfer by the ribs in both directions $a$ and $b$ at thickness of $4 \mathrm{~cm}$ of slab equals $100 \%$. But with increasing the thickness of slab, $25 \%$ of total load transfer by ribs and $75 \%$ transfer by slab at thickness of $16 \mathrm{~cm}$. 
The coefficients $(\alpha)$ and $(\beta)$ at thickness of $4 \mathrm{~cm}$ of slab equal 0.79 and 0.22 respectively and $(\alpha),\left({ }^{\beta}\right)$ at thickness of $16 \mathrm{~cm}$ of slab equal 0.17 and 0.08 respectively.

The values of S.F and B.M in direction 'a` at thickness of $16 \mathrm{~cm}$ of slab $8^{*} 10$ are $13 \%$ and $34.3 \%$ the values of S.F and B.M at thickness of $4 \mathrm{~cm}$ of slab respectively .

Also, the values of S.F and B.M in direction ' $b$ ' at thickness of $16 \mathrm{~cm}$ of slab are $15.3 \%$ and $48.3 \%$ the values of S.F and B.M at thickness of $4 \mathrm{~cm}$ of slab respectively.

The percentage of the load transfer by the ribs in both directions a and $b$ at thickness of $4 \mathrm{~cm}$ of slab equals $100 \%$. With increasing the thickness of slab $24.8 \%$ of total load transfer by ribs and $75.2 \%$ transfer by slab at thickness of $16 \mathrm{~cm}$.

The coefficients $(\alpha)$ and $(\beta)$ at thickness of $4 \mathrm{~cm}$ of slab equal to 0.67 and 0.36 respectively. $(\alpha)$ and $(\beta)$ at thickness of $16 \mathrm{~cm}$ are 0.14 and 0.1 respectively.

The values of S.F and B.M at thickness of $16 \mathrm{~cm}$ of slab $10 * 10$ where direction $\mathrm{a}=$ direction $\mathrm{b}$ are $13.17 \%$ and $39.3 \%$ the values of S.F and B.M at thickness of $4 \mathrm{~cm}$ respectively.

The percentage of the load transfer by the ribs in both directions a and $b$ at thickness of $4 \mathrm{~cm}$ of slab equals $100 \%$. With increasing the thickness of slab, $25.2 \%$ of total load transfer by ribs and $74.8 \%$ transfer by slab at thickness of $16 \mathrm{~cm}$.

Also, the coefficients $(\alpha)=\left({ }^{\beta}\right)$ at thickness of $4 \mathrm{~cm}$ of slab equal 0.5 and $(\alpha)=(\beta)$ at thickness $16 \mathrm{~cm}$ of slab equal to 0.15 .

Also, the produced B.M at the connecting between rib and solid part in each direction $a$ and $b$ changes with the change of slab thickness. This moment is negative for slabs with thickness of $4 \mathrm{~cm}$ and then decreases when the thickness increases until the value of moment reaches to zero or positive values for slabs with thickness of 16 $\mathrm{cm}$.

\subsubsection{Effect of the depth of rib}

The effect of the depth of rib on the internal forces was studied. This analysis is divided into two parts, the first is concerned with one way ribbed slabs and the second is concerned with two way ribbed slabs.

\section{A) One way ribbed slabs.}

Slabs of dimensions $(4 * 10,6 * 10,8 * 1010 * 10$ and $12 * 10)$ were analyzed. These slabs had ribs in one direction. The ribs had depth $(0.15,0.2$ and 0.25$) \mathrm{m}$ and constant width $0.1 \mathrm{~m}$. The slabs had solid parts in two directions, direction parallel to ribs and perpendicular to ribs with width $0.5 \mathrm{~m}$ and $0.8 \mathrm{~m}$ respectively. The thickness of solid parts was the same depth of the ribs. The S.Fs and B.Ms of the middle rib for slabs $(4 * 10,6 * 10,8 * 10,10 * 10$, and $12 * 10)$ are tabled as follows :- 
Table (15)

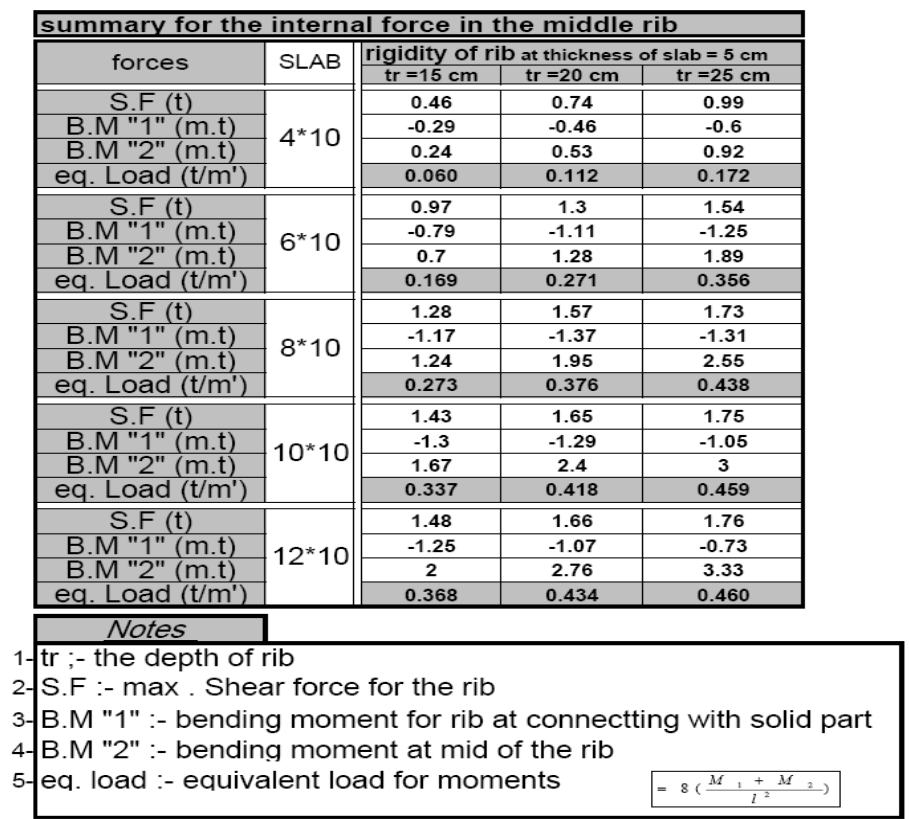

The produced shear force and bending moments in the rib increase as the depth of rib increases.

The values of S.F for slabs $(4 * 10,6 * 10,8 * 10,10 * 10$ and $12 * 10)$ with depth of $25 \mathrm{~cm}$ of rib are $2.15,1.59,1.35,1.23$, and 1.19 the values of S.F with depth of $15 \mathrm{~cm}$ respectively.

The values of positive B.M for slabs $(4 * 10,6 * 10,8 * 10,10 * 10$ and $12 * 10)$ with depth of $25 \mathrm{~cm}$ of rib are 3.83, 2.7, 2.05, 1.8, and 1.66 the values of B.M with depth of $15 \mathrm{~cm}$ respectively.

Also, the values of the equivalent load for slabs $(4 * 10,6 * 10,8 * 10,10 * 10$ and $12 * 10$ ) with depth of $25 \mathrm{~cm}$ of rib are $2.86,2.1,1.6,1.36$ and 1.25 the values of the equivalent loads with depth of $15 \mathrm{~cm}$ respectively.

The value of negative B.M at the connection of the rib with solid part increase as the rib depth increases, when the ratio of width of slab "a" to length of slab "b" $<1.0$. And by increasing the ratio $\boldsymbol{a} / \boldsymbol{b}$ over 1.0, the negative B.M decreases as the depth of rib increases. This may be because great decrease happens in the rigidity of solid part which related with the rib and decrease the restriction of the rib's movement.

\section{B) Two way ribbed slabs.}

Ribbed slabs of dimensions $\left(6 * 10,8^{*} 10\right.$ and $\left.10 * 10\right)$ were analyzed. These slabs had ribs in two directions. The depth of rib were $(15,20$ and 25$) \mathrm{cm}$ and the width equals to $10 \mathrm{~cm}$. The thickness of slab equals to $5 \mathrm{~cm}$. The slabs had solid parts in two directions, direction parallel to ribs and perpendicular to ribs with width $0.5 \mathrm{~m}$. The thickness of solid parts was the same depth of the ribs.

The S.Fs and B.Ms produced in the middle rib in each direction for slabs $(6 * 10),(8 * 10)$ and $(10 * 10)$ are shown in Tables (16) and (17). 
Table 16 direction a

Table (17) direction $\mathrm{b}$

\begin{tabular}{|c|c|c|c|c|c|c|c|c|c|}
\hline \multicolumn{5}{|c|}{ summary for the internal force in the middle rib direction a } & \multicolumn{5}{|c|}{ summary for the internal force in the middle rib direction $\mathrm{k}$} \\
\hline \multirow{2}{*}{ forces } & \multirow{2}{*}{ SLAB } & \multicolumn{3}{|c|}{ rigidity of rib at thickness of slab $=5 \mathrm{~cm}$} & \multirow{2}{*}{ forces } & \multirow{2}{*}{ SLAB } & \multicolumn{3}{|c|}{ rigidity of rib at thickness of slab $=5 \mathrm{~cm}$} \\
\hline & & $\operatorname{tr}=15 \mathrm{~cm}$ & $\operatorname{tr}=20 \mathrm{~cm}$ & $\operatorname{tr}=25 \mathrm{~cm}$ & & & $\operatorname{tr}=15 \mathrm{~cm}$ & $\operatorname{tr}=20 \mathrm{~cm}$ & $\operatorname{tr}=25 \mathrm{~cm}$ \\
\hline S.F (t) & \multirow{4}{*}{$6 * 10$} & 0.77 & 0.83 & 0.88 & S.F (t) & \multirow{4}{*}{$6 * 10$} & 0.66 & 0.74 & 0.81 \\
\hline B.M "1" (m.t) & & -0.34 & -0.23 & -0.09 & B.M "1" (m.t) & & -0.42 & -0.37 & -0.24 \\
\hline B.M "2" (m.t) & & 0.72 & 0.95 & 1.1 & B.M "2" (m.t) & & 0.39 & 0.68 & 1.04 \\
\hline eq. Load (t/m') & & 0.353 & 0.393 & 0.396 & eq. Load (t/m') & & 0.082 & 0.106 & 0.129 \\
\hline S.F $(t)$ & \multirow{4}{*}{$8 * 10$} & 1 & 1.06 & 1.07 & S.F $(t)$ & \multirow{4}{*}{$8 * 10$} & 0.91 & 0.98 & 1.02 \\
\hline B.M "1" (m.t) & & -0.7 & -0.55 & -0.33 & B.M "1" (m.t) & & -0.71 & -0.61 & -0.4 \\
\hline B.M "2" (m.t) & & 1 & 1.36 & 1.62 & B.M "2" (m.t) & & 0.75 & 1.15 & 1.55 \\
\hline eq. Load (t/m') & & 0.286 & 0.321 & 0.328 & eq. Load (t/m') & & 0.147 & 0.178 & 0.198 \\
\hline S.F $(t)$ & \multirow{4}{*}{$10 * 10$} & 1.13 & 1.19 & 1.19 & S.F $(t)$ & \multirow{4}{*}{$10 * 10$} & 1.13 & 1.19 & 1.19 \\
\hline B.M "1" (m.t) & & -0.96 & -0.79 & -0.48 & B.M "1" (m.t) & & -0.96 & -0.79 & -0.48 \\
\hline B.M "2" (m.t) & & 1.16 & 1.67 & 2.1 & B.M "2" (m.t) & & 1.16 & 1.67 & 2.1 \\
\hline eq. Load (t/m') & & 0.214 & 0.248 & 0.260 & eq. Load (t/m') & & 0.214 & 0.248 & 0.260 \\
\hline
\end{tabular}

The produced internal forces in the ribs in each direction decrease as the depth of rib increases.

The values of S.F and positive B.M in direction `a for slab $6 * 10$ at depth of 25 $\mathrm{cm}$ of rib are 1.14 and 1.52 the values of S.F and B.M at depth of $15 \mathrm{~cm}$ of rib respectively.

Also, the values of S.F and positive B.M in direction 'b` at depth of $25 \mathrm{~cm}$ of rib are 1.22 and 2.66 the values of S.F and positive B.M at depth of $15 \mathrm{~cm}$ of rib respectively .

The equivalent load in direction 'a' and 'b' at depth of $15 \mathrm{~cm}$ of rib are 0.435 $\mathrm{t} / \mathrm{m}$ ', this means that $87 \%$ of the total load transfer by ribs in each direction 'a' and 'b' and $13 \%$ by slab. But with increasing the depth of rib until reaches to $25 \mathrm{~cm}, 100 \%$ of total load transfer by ribs.

The coefficients $(\alpha)$ and $(\beta)$ at depth of $15 \mathrm{~cm}$ of rib equal 0.7 and 0.16 respectively and $(\alpha),\left({ }^{\beta}\right)$ at depth of $25 \mathrm{~cm}$ of rib equal 0.78 and 0.25 respectively.

The values of S.F and positive B.M in direction `a ' for slab $8 * 10$ at depth of 25 $\mathrm{cm}$ of slab are 1.07 and 1.62 the values of S.F and positiveB.M at depth of $15 \mathrm{~cm}$ of rib respectively .

Also, the values of S.F and positive B.M in direction 'b` at depth of $25 \mathrm{~cm}$ of rib are 1.12 and 2.08 the values of S.F and positive B.M at depth of $15 \mathrm{~cm}$ of rib respectively.

The equivalent loads in directions 'a' and 'b' at depth of $15 \mathrm{~cm}$ of rib are 0.433 $\mathrm{t} / \mathrm{m}$ ', this means that $86.6 \%$ of the total load transfer by ribs in each direction 'a' and ' $\mathrm{b}$ ' and $13.4 \%$ by slab. But with increasing the depth of rib until reaches to $25 \mathrm{~cm}, 100 \%$ of total load transfer by ribs.

The coefficients $(\alpha)$ and $(\beta)$ at depth of $15 \mathrm{~cm}$ of rib equal $0.56,0.28$ respectively. $(\alpha)$ and $(\beta)$ at depth of $25 \mathrm{~cm}$ are $0.64,0.39$ respectively.

The values of S.F and positive B.M for slab $10 * 10$ where direction $\mathrm{a}=$ direction $\mathrm{b}$ at depth of $25 \mathrm{~cm}$ of rib are 1.05 and 1.8 the values of S.F and positiveB.M at depth of $15 \mathrm{~cm}$ respectively.

The equivalent load in direction 'a' and 'b' at depth of $15 \mathrm{~cm}$ of rib are 0.428 $\mathrm{t} / \mathrm{m}$ ', this means that $85.6 \%$ of the total load transfer by ribs in each direction 'a' and 'b' and $14.4 \%$ by slab. But with increasing the depth of rib until reaches to $25 \mathrm{~cm}, 100 \%$ of total load transfer by ribs. 
The coefficients $(\alpha)$ and $(\beta)$ at depth of $15 \mathrm{~cm}$ of rib equal 0.42 and $(\alpha)$ and $(\beta)$ at depth of $25 \mathrm{~cm}$ of rib equal 0.52 .

The previous results show that the rate of increase of load when the rib depth increase from $15 \mathrm{~cm}$ to $25 \mathrm{~cm}$ is lower than the rate of increase of load in one way slab.

The increase of load of the ribs in each direction when the depth of rib increases from $15 \mathrm{~cm}$ to $25 \mathrm{~cm}$ is small, but there are large difference in positive B.M of ribs in each direction ' $a$ ' and ' $b$ '. This may be because the produced negative B.M at the connection between ribs and solid part is large at depth $15 \mathrm{~cm}$ of rib which causes decrease positive B.M, while at depth $25 \mathrm{~cm}$ of rib, the negative B.M is very small , this causes increase in positive B.M.

\subsubsection{Effect of the width of slab:-}

The effect of change of the width of slab on the internal forces with fixing both the depth of rib and slab thickness were studied in one way and two way ribbed slabs.

\section{A) one way ribbed slab}

The same slabs of dimensions $(4 * 10,6 * 10,8 * 10,10 * 10$ and $12 * 10)$ were analyzed with fixing the depth of rib and slab thickness at $20 \mathrm{~cm}$ and $4 \mathrm{~cm}$ respectively. The S.F and B.M of slabs $(4 * 10,6 * 10,8 * 10,10 * 10$ and $12 * 10)$ are shown in Table (18).

Table (18)

\begin{tabular}{|c|c|c|c|c|c|}
\hline \multirow{2}{*}{ forces } & \multicolumn{5}{|c|}{ Slabs } \\
\cline { 2 - 6 } & $4^{*} 10$ & $6^{*} 10$ & $8^{*} 10$ & $10^{*} 10$ & $12^{*} 10$ \\
\hline \hline S.F (t) & 0.96 & 1.54 & 1.74 & 1.77 & 1.78 \\
\hline B.M1 (m.t) & -0.7 & -1.45 & -1.62 & -1.44 & -1.17 \\
\hline B.M2 (m.t) & 0.64 & 1.5 & 2.1 & 2.52 & 2.87 \\
\hline eq. load t/m & 0.150 & 0.336 & 0.421 & 0.449 & 0.458 \\
\hline
\end{tabular}

The produced shear force and bending moments in the rib increase as the width of slab increases.

The values of S.F and positive B.M for slab $12 * 10$ are 1.85 and 4.48 the values of S.F and positive B.M for slab $4 * 10$ respectively.

The value of equivalent load for slab $12 * 10$ is 3.05 the value of equivalent load for slab $4 * 10$.

The previous behavior was similar for all different cases of slab thickness and depth of rib

\section{B) Two way ribbed slab}

The same slabs of dimensions $(6 * 10,8 * 10$ and $10 * 10)$ were analyzed with fixing the depth of rib and slab thickness at $20 \mathrm{~cm}$ and $4 \mathrm{~cm}$ respectively. The S.F and B.M of slabs $\left(6 * 10,8 * 10\right.$ and $\left.10^{*} 10\right)$ in direction 'a' and 'b' are shown in Tables (19 and 20).

Table (19) Direction a

\begin{tabular}{|c||c|c|c|}
\hline \multicolumn{1}{|c|}{ forces } & $6^{* 10}$ & $8^{* 10}$ & $10^{*} 10$ \\
\hline \hline S.F (t) & 0.93 & 1.15 & 1.29 \\
\hline B.M "1" (m.t) & -0.26 & -0.62 & -0.88 \\
\hline B.M "2" (m.t) & 0.93 & 1.4 & 1.72 \\
\hline eq. Load (t/m') & 0.396 & 0.339 & 0.262 \\
\hline
\end{tabular}


The produced shear force and bending moments in the rib in direction "a" increase as the width of slab increases. While the maximum value of equivalent load was at width $6 \mathrm{~m}$ and the minimum value was at width of slab of $10 \mathrm{~m}$.

The values of S.F and positive B.M of the ribs in direction 'a' for slab $10 * 10$ are 1.38 , and 1.85 the values of S.F and positive B.M for slab $6^{*} 10$ respectively.

The value of equivalent load of the ribs in direction ' $a$ ' for slab $10^{*} 10$ is 0.66 the value of equivalent load for slab $6 * 10$.

Table (20) Direction b

\begin{tabular}{|c||c|c|c|}
\hline \multicolumn{2}{|c|}{ forces } & \multicolumn{3}{|c|}{ slabs } \\
\cline { 2 - 4 } & $6^{* 10}$ & $8^{* 10}$ & $10^{* 10}$ \\
\hline S.F (t) & 0.81 & 1.05 & 1.29 \\
\hline B.M "1" (M.t) & -0.41 & -0.68 & -0.88 \\
\hline B.M "2" (M.t) & 0.7 & 1.18 & 1.72 \\
\hline eq. Load (t/m") & 0.112 & 0.188 & 0.262 \\
\hline
\end{tabular}

The produced shear force and bending moments in the rib in direction " $\mathrm{b}$ increase as the width of slab increases. Also the minimum value of equivalent load was at width of slab of $6 \mathrm{~m}$ and the maximum value of equivalent load was at width of slab of $10 \mathrm{~m}$

The values of S.F and positive B.M for slab $10 * 10$ of the ribs in direction 'b' are 1.6 and 2.46 the values of S.F for slab $6 * 10$ respectively.

The value of equivalent load of the ribs in direction ' $b$ ' for slab $10 * 10$ is 2.34 the value of equivalent load for slab $6^{*} 10$.

The previous behavior was similar for all different cases of slab thickness and depth of rib.

\subsubsection{The Location of rib}

The effect of slab thickness and the depth of rib on the internal forces were studied for the ribs which are located in quarter of slab and another rib located at the slab edge for different slab thickness and depth of the middle rib.

The S.Fs and B.Ms of the quarter rib for one way slabs $\left(4 * 10,6 * 10,8^{*} 10\right.$, $10 * 10$, and $12 * 10$ ) are shown in Table (21)

Table (21)

\begin{tabular}{|c|c|c|c|c|c|c|c|c|c|}
\hline \multicolumn{7}{|c|}{ summary for the internal force in the qurter of slab } & & & \\
\hline \multirow{2}{*}{ forces } & \multirow{2}{*}{ SLAB } & \multicolumn{5}{|c|}{ rigidity of slab at depth of ribs $=20 \mathrm{~cm}$} & \multicolumn{3}{|c|}{ rigidity of rib at thickness of slab $=5 \mathrm{~cm}$} \\
\hline & & ts $=4 \mathrm{~cm}$ & ts $=5 \mathrm{~cm}$ & ts $=8 \mathrm{~cm}$ & ts $=12 \mathrm{~cm}$ & ts $=16 \mathrm{~cm}$ & $\mathrm{tr}=15 \mathrm{~cm}$ & $\mathrm{tr}=20 \mathrm{~cm}$ & $\mathrm{tr}=25 \mathrm{~cm}$ \\
\hline S.F $(t)$ & \multirow{3}{*}{$4 * 10$} & 0.83 & 0.66 & 0.37 & 0.19 & 0.11 & 0.45 & 0.66 & 0.87 \\
\hline B.M"1" (m.t) & & -0.54 & -0.36 & -0.1 & 0 & 0.08 & -0.24 & -0.36 & -0.45 \\
\hline B.M"2" (m.t) & & 0.58 & 0.5 & 0.4 & 0.35 & 0.3 & 0.22 & 0.5 & 0.85 \\
\hline$S . F(t)$ & \multirow{3}{*}{$6 * 10$} & 1.25 & 1.04 & 0.58 & 0.24 & 0.14 & 0.76 & 1.04 & 1.27 \\
\hline B.M "1" (m.t) & & -1.05 & -0.77 & -0.25 & 0.02 & 0.09 & -0.56 & -0.77 & -0.85 \\
\hline B.M "2" (m.t) & & 1.25 & 1.07 & 0.75 & 0.56 & 0.45 & 0.57 & 1.07 & 1.6 \\
\hline$S . F(t)$ & \multirow{3}{*}{$8 * 10$} & 1.48 & 1.29 & 0.74 & 0.29 & 0.17 & 1 & 1.29 & 1.5 \\
\hline B.M"1" (m.t) & & -1.23 & -0.96 & -0.34 & 0 & 0.11 & -0.82 & -0.96 & -0.94 \\
\hline B.M "2" (m.t) & & 1.76 & 1.57 & 1.14 & 0.79 & 0.57 & 0.96 & 1.57 & 2.17 \\
\hline S.F $(\mathrm{t})$ & \multirow{3}{*}{$10 * 10$} & 1.62 & 1.44 & 0.85 & 0.34 & 0.2 & 1.16 & 1.44 & 1.62 \\
\hline B.M "1" (m.t) & & -1.24 & -1 & -0.36 & 0 & 0.12 & -0.94 & -1 & -0.9 \\
\hline B.M "2" (m.t) & & 2.19 & 2 & 1.49 & 1 & 0.67 & 1.3 & 2 & 2.64 \\
\hline$S . F(t)$ & \multirow{3}{*}{$12 * 10$} & 1.7 & 1.54 & 0.94 & 0.38 & 0.21 & 1.13 & 1.54 & 1.7 \\
\hline B.M"1" (m.t) & & -1.15 & -0.94 & -0.33 & 0.05 & 0.12 & -0.97 & -0.94 & -0.76 \\
\hline B.M" "2" (m.t) & & 2.55 & 2.37 & 1.8 & 1.17 & 0.75 & 1.6 & 2.37 & 3 \\
\hline
\end{tabular}

The S.F and B.M of the ribs are maximum values at thickness of $4 \mathrm{~cm}$ of slab, and then decrease until reach to the minimum values at thickness of $16 \mathrm{~cm}$ of slab. 
Also, with increasing the depth of rib, the S.F and B.M.D increase until reach to maximum values at depth of $25 \mathrm{~cm}$.

The values of S.F for slabs $(4 * 10,6 * 10,8 * 10,10 * 10$ and $12 * 10)$ with thickness of $16 \mathrm{~cm}$ are $13.3 \%, 11.2 \%, 11.5 \%, 12.4 \%$ and $12.35 \%$ the values of S.F with thickness of $4 \mathrm{~cm}$ respectively.

The values of positive B.M for slabs $(4 * 10,6 * 10,8 * 10,10 * 10$ and $12 * 10)$ with thickness of $16 \mathrm{~cm}$ are $51,7 \%, 36.8 \%, 32.4 \%, 30.6 \%$ and $29.4 \%$ the values of B.M with thickness of $4 \mathrm{~cm}$ respectively.

The values of the equivalent loads for slabs $(4 * 10,6 * 10,8 * 10,10 * 10$ and $12 * 10)$ with thickness of $16 \mathrm{~cm}$ are $19.8 \%, 15.3 \%, 15.3 \%, 15.9 \%$ and $16.9 \%$ the values of the equivalent loads at thickness of $4 \mathrm{~cm}$ respectively.

The values of S.F for slabs $(4 * 10,6 * 10,8 * 10,10 * 10$ and $12 * 10)$ with depth of $25 \mathrm{~cm}$ of rib are $1.89,1.67,1.5,1.4$ and 1.5 the values of S.F with depth of $15 \mathrm{~cm}$ respectively.

The values of positive B.M for slabs $(4 * 10,6 * 10,8 * 10,10 * 10$ and $12 * 10)$ with depth of $25 \mathrm{~cm}$ of rib are 3.86, 2.8, 2.28, 2, and 1.88 the values of B.M at depth of $15 \mathrm{~cm}$ respectively.

Also, the values of the equivalent loads for slabs $(4 * 10,6 * 10,8 * 10,10 * 10$ and $12 * 10)$ with depth of $25 \mathrm{~cm}$ of rib are $2.88,2.13,1.75,1.6$ and 1.46 the values of the equivalent loads with depth of $15 \mathrm{~cm}$ respectively.

The S.F.s and B.M.s of the edge rib for slabs $(4 * 10,6 * 10,8 * 10,10 * 10$, and $12 * 10)$ are shown in table (22)

Table 22

\begin{tabular}{|c|c|c|c|c|c|c|c|c|c|}
\hline \multicolumn{10}{|c|}{ summary for the internal force at the slab edge } \\
\hline \multirow{2}{*}{ forces } & \multirow{2}{*}{ SLAB } & \multicolumn{5}{|c|}{ rigidity of slab at depth of ribs $=20 \mathrm{~cm}$} & \multicolumn{3}{|c|}{ rigidity of rib at thickness of slab $=5 \mathrm{~cm}$} \\
\hline & & $\mathrm{ts}=4 \mathrm{~cm}$ & ts $=5 \mathrm{~cm}$ & ts $=8 \mathrm{~cm}$ & ts $=12 \mathrm{~cm}$ & ts $=16 \mathrm{~cm}$ & $\mathrm{tr}=15 \mathrm{~cm}$ & $\mathrm{tr}=20 \mathrm{~cm}$ & $\operatorname{tr}=25 \mathrm{~cm}$ \\
\hline$S . F(t)$ & \multirow{3}{*}{$4 * 10$} & 0.43 & 0.39 & 0.28 & 0.17 & 0.1 & 0.26 & 0.39 & 0.5 \\
\hline \multirow{2}{*}{$\begin{array}{l}\text { B.M "1" (m.t) } \\
\text { B.M "2" (m.t) }\end{array}$} & & -0.12 & -0.06 & 0 & 0.07 & 0.09 & -0.07 & -0.06 & 0 \\
\hline & & 0.44 & 0.41 & 0.37 & 0.33 & 0.3 & 0.2 & 0.41 & 0.71 \\
\hline$S . F(t)$ & \multirow{3}{*}{$6 * 10$} & 0.85 & 0.7 & 0.43 & 0.23 & 0.14 & 0.5 & 0.7 & 0.9 \\
\hline \multirow{2}{*}{$\begin{array}{l}\text { B.M "1" (m.t) } \\
\text { B.M "2" (m.t) }\end{array}$} & & -0.54 & -0.37 & -0.09 & 0.06 & 0.11 & -0.3 & -0.37 & -0.35 \\
\hline & & 0.95 & 0.84 & 0.66 & 0.53 & 0.44 & 0.44 & 0.84 & 1.3 \\
\hline \multirow{3}{*}{$\frac{S . F(t)}{\text { B.M "1" (m.t) }}$} & \multirow{3}{*}{$8 * 10$} & 0.78 & 0.62 & 0.41 & 0.26 & 0.16 & 0.41 & 0.62 & 0.85 \\
\hline & & -0.28 & -0.13 & 0 & 0.12 & 0.13 & -0.19 & -0.13 & 0 \\
\hline & & 1.09 & 1 & 0.84 & 0.67 & 0.53 & 0.57 & 1 & 1.48 \\
\hline$S . F(t)$ & \multirow{3}{*}{$10 * 10$} & 0.73 & 0.58 & 0.43 & 0.31 & 0.18 & 0.33 & 0.58 & 0.82 \\
\hline \multirow{2}{*}{$\begin{array}{l}\text { B.M "1" (m.t) } \\
\text { B.M "2" (m.t) }\end{array}$} & & -0.05 & 0.1 & 0.2 & 0.18 & 0.15 & 0 & 0.1 & 0.23 \\
\hline & & 1.19 & 1.1 & 0.96 & 0.79 & 0.6 & 0.64 & 1.1 & 1.62 \\
\hline \multirow{3}{*}{$\begin{array}{c}\frac{S . F(t)}{B . M^{\prime \prime} 1 "(m . t)} \\
\text { B.M "2" (m.t) }\end{array}$} & \multirow{3}{*}{$12 * 10$} & 0.68 & 0.55 & 0.45 & 0.34 & 0.2 & 0.3 & 0.55 & 0.8 \\
\hline & & 0.13 & 0.29 & 0.34 & 0.24 & 0.16 & 0.11 & 0.29 & 0.42 \\
\hline & & 1.28 & 1.2 & 1.04 & 0.85 & 0.65 & 0.69 & 1.2 & 1.74 \\
\hline
\end{tabular}

The behavior of the edge rib has the same trend as the rib in the quarter of the slab. So the S.F and B.M of the rib are maximum values at thickness of $4 \mathrm{~cm}$ of slab, and then decrease until reach to the minimum values at thickness of $16 \mathrm{~cm}$ of slab. Also, with increasing the depth of rib, the S.F and B.M.D increase until reach to maximum values at depth of $25 \mathrm{~cm}$.

The values of S.F for slabs $(4 * 10,6 * 10,8 * 10,10 * 10$ and $12 * 10)$ with thickness of $16 \mathrm{~cm}$ are $23.3 \%, 16.5 \%, 20.5 \%, 24.7 \%$ and $29.4 \%$ the values of S.F with thickness of $4 \mathrm{~cm}$ respectively.

The values of positive B.M for slabs $(4 * 10,6 * 10,8 * 10,10 * 10$ and $12 * 10)$ with thickness of $16 \mathrm{~cm}$ are $68.2 \%, 46.30 \%, 48.60 \%, 50.4 \%$ and $50.8 \%$ the values of B.M with thickness of $4 \mathrm{~cm}$ respectively. 
The values of the equivalent loads for slabs $(4 * 10,6 * 10,8 * 10,10 * 10$ and $12 * 10)$ with thickness of $16 \mathrm{~cm}$ are $38 \%, 22 \%, 29 \%, 36 \%$ and $42.3 \%$ the values of the equivalent load with thickness of $4 \mathrm{~cm}$ respectively.

The values of S.F for slabs $(4 * 10,6 * 10,8 * 10,10 * 10$ and $12 * 10)$ with depth of $25 \mathrm{~cm}$ of rib are 1.92, 1.8, 2.07, 2.48 and 2.66 the values of S.F with depth of $15 \mathrm{~cm}$ respectively.

The values of positive B.M for slabs $(4 * 10,6 * 10,8 * 10,10 * 10$ and $12 * 10)$ with depth of $25 \mathrm{~cm}$ of rib are 3.55, 2.95, 2.6, 2.53 and 2.52 the values of B.M with depth of $15 \mathrm{~cm}$ respectively.

The values of the equivalent loads for slabs $(4 * 10,6 * 10,8 * 10,10 * 10$ and $12 * 10)$ with depth of $25 \mathrm{~cm}$ of rib are $2.66,2.23,1.94,2.15$ and 2.3 the values of the equivalent loads with depth of $15 \mathrm{~cm}$ respectively.

The produced B.M at the connection between rib and solid part in the rib in the quarter of slab and the edge is negative at thickness $4 \mathrm{~cm}$ of slabs then decreases with increasing the thickness until reaches zero or positive value at thickness of $16 \mathrm{~cm}$ of slabs.

The produced S.F and B.M in the middle rib are bigger than S.F and B.M in other ribs at thickness $4 \mathrm{~cm}$. The difference in the internal forces between the ribs decrease as the slab thickness increases. This difference reaches to the minimum values at thickness of $16 \mathrm{~cm}$ of slab.

Also, the difference in the internal forces between the ribs decrease with increasing the depth of the rib for all slabs except in slab $4 * 10$ where the difference in the internal forces between the ribs increases with increasing the depth of the rib.

Comparison of the internal forces between the middle rib, the quarter rib and the edge rib with change the slab thickness is shown in tables 23.

Table 23

\begin{tabular}{|c|c|c|c|c|c|c|c|c|c|c|c|c|c|c|c|c|}
\hline \multicolumn{17}{|c|}{$\begin{array}{l}\text { Comparing the internal force with changing thickness of slab } \\
\text { rigidity of slab at dep }\end{array}$} \\
\hline \multirow{2}{*}{ forces } & \multirow{2}{*}{ SLAB } & \multicolumn{3}{|c|}{ ts $=4 \mathrm{~cm}$} & \multicolumn{3}{|c|}{$\mathrm{ts}=5 \mathrm{~cm}$} & \multicolumn{3}{|c|}{ ts $=8 \mathrm{~cm}$} & \multicolumn{3}{|c|}{$\mathrm{ts}=12 \mathrm{~cm}$} & \multicolumn{3}{|c|}{$\mathrm{ts}=16 \mathrm{~cm}$} \\
\hline & & $\begin{array}{l}\text { at the } \\
\text { edge }\end{array}$ & \begin{tabular}{|l} 
in \\
qurter
\end{tabular} & \begin{tabular}{|c} 
in \\
middle
\end{tabular} & \begin{tabular}{|l|} 
at the \\
edge
\end{tabular} & $\begin{array}{l}\text { in } \\
\text { qurter }\end{array}$ & \begin{tabular}{|c} 
in \\
middle
\end{tabular} & $\begin{array}{l}\text { at the } \\
\text { edge }\end{array}$ & \begin{tabular}{|c|} 
in \\
quirter
\end{tabular} & \begin{tabular}{|c} 
in \\
middle
\end{tabular} & \begin{tabular}{|l} 
at the \\
edge
\end{tabular} & \begin{tabular}{|c|} 
in \\
qurter
\end{tabular} & \begin{tabular}{|c} 
in \\
middle
\end{tabular} & $\begin{array}{l}\text { at the } \\
\text { edge }\end{array}$ & \begin{tabular}{|c|} 
in \\
qurter
\end{tabular} & \begin{tabular}{|c} 
in \\
middle
\end{tabular} \\
\hline \multirow{3}{*}{\begin{tabular}{c|}
$\frac{S . F}{}$ \\
B.M"1" \\
B.M"2"
\end{tabular}} & \multirow{3}{*}{$4^{*} 10$} & 0.43 & 0.83 & 0.96 & 0.39 & 0.66 & 0.74 & 0.28 & 0.37 & 0.42 & 0.17 & 0.19 & 0.19 & 0.1 & 0.11 & 0.11 \\
\hline & & -0.12 & -0.54 & -0.7 & -0.06 & -0.36 & -0.46 & 0 & -0.1 & -0.14 & 0.07 & 0 & 0.03 & 0.09 & 0.08 & 0.07 \\
\hline & & 0.44 & 0.58 & 0.64 & 0.41 & 0.5 & 0.53 & 0.37 & 0.4 & 0.41 & 0.33 & 0.35 & 0.35 & 0.3 & 0.3 & 0.3 \\
\hline S.F & \multirow{3}{*}{$6 * 10$} & 0.85 & 1.25 & 1.54 & 0.7 & 1.04 & 1.3 & 0.43 & 0.58 & 0.7 & 0.23 & 0.24 & 0.24 & 0.14 & 0.14 & 0.15 \\
\hline \multirow{2}{*}{$\frac{6 . M^{\prime \prime} 1 "}{\text { B.M"2" }}$} & & -0.54 & -1.05 & -1.46 & -0.37 & -0.77 & -1.11 & -0.09 & -0.25 & -0.38 & 0.06 & 0.02 & 0 & 0.11 & 0.09 & 0.09 \\
\hline & & 0.95 & 1.25 & 1.5 & 0.84 & 1.07 & 1.28 & 0.66 & 0.75 & 0.84 & 0.53 & 0.56 & 0.59 & 0.44 & 0.45 & 0.45 \\
\hline \multirow{3}{*}{\begin{tabular}{|l|} 
S.F \\
B.M"1" \\
B.M"2"
\end{tabular}} & \multirow{3}{*}{$8 * 10$} & 0.78 & 1.48 & 1.74 & 0.62 & 1.29 & 1.57 & 0.41 & 0.74 & 0.92 & 0.26 & 0.29 & 0.34 & 0.16 & 0.17 & 0.17 \\
\hline & & -0.28 & -1.23 & -1.62 & -0.13 & -0.96 & -1.37 & 0 & -0.34 & -0.57 & 0.12 & 0 & -0.03 & 0.13 & 0.11 & 0.09 \\
\hline & & 1.09 & 1.76 & 2.1 & 1 & 1.57 & 1.95 & 0.84 & 1.14 & 1.34 & 0.67 & 0.79 & 0.86 & 0.53 & 0.57 & 0.6 \\
\hline \multirow{3}{*}{$\begin{array}{c}\text { S.F } \\
\text { B.M"1"1" } \\
\text { B.M "2" }\end{array}$} & \multirow{3}{*}{$10 * 10$} & 0.73 & 1.62 & 1.77 & 0.58 & 1.44 & 1.65 & 0.43 & 0.85 & 1.04 & 0.31 & 0.34 & 0.35 & 0.18 & 0.2 & 0.2 \\
\hline & & -0.05 & -1.24 & -1.44 & 0.1 & -1 & -1.29 & 0.2 & -0.36 & -0.6 & 0.18 & 0 & -0.03 & 0.15 & 0.12 & 0.08 \\
\hline & & 1.19 & 2.19 & 2.52 & 1.1 & 2 & 2.4 & 0.96 & 1.49 & 1.8 & 0.79 & 1 & 1.12 & 0.6 & 0.67 & 0.71 \\
\hline S.F & \multirow{3}{*}{$12 * 10$} & 0.68 & 1.7 & 1.78 & 0.55 & 1.54 & 1.66 & 0.45 & 0.94 & 1.1 & 0.34 & 0.38 & 0.42 & 0.2 & 0.21 & 0.21 \\
\hline \multirow{2}{*}{$\begin{array}{l}\text { B.M"1" } \\
\text { B.M 2" } \\
\end{array}$} & & 0.13 & -1.15 & -1.17 & 0.29 & -0.94 & -1.07 & 0.34 & -0.33 & -0.52 & 0.24 & 0.05 & 0 & 0.16 & 0.12 & 0.1 \\
\hline & & 1.28 & 2.55 & 2.87 & 1.2 & 2.37 & 2.76 & 1.04 & 1.8 & 2.15 & 0.85 & 1.17 & 1.34 & 0.65 & 0.75 & 0.8 \\
\hline
\end{tabular}

The comparison between the middle rib and quarter rib at (thickness of slab of 4and $16 \mathrm{~cm}$ with constant rib depth) is as follows:-

The values of S.F of the middle rib for slabs $(4 * 10,6 * 10,8 * 10,10 * 10$ and $12 * 10)$ with thickness of $4 \mathrm{~cm}$ are $1.15,1.23,1.17,1.09$ and 1.05 the values of S.F of the quarter rib respectively.

The values of S.F of the middle rib for slabs $\left(4 * 10,6 * 10,8 * 10,10^{*} 10\right.$ and $12 * 10)$ with thickness of $16 \mathrm{~cm}$ are $1.0,1.07,1.0,1.0$ and 1.0 the values of S.F of the quarter rib respectively. 
The values of positive B.M of the middle rib for slabs $\left(4 * 10,6 * 10,8^{*} 10\right.$, $10 * 10$ and $12 * 10)$ with thickness of $4 \mathrm{~cm}$ are $1.1,1.2,1.19,1.15$ and 1.12 the values of B.M of the quarter rib respectively.

The values of positive B.M of the middle rib for slabs $(4 * 10,6 * 10,8 * 10$, $10 * 10$ and $12 * 10$ ) with thickness of $16 \mathrm{~cm}$ are $1,1,1.05,1.06$ and 1.06 the values of B.M of the quarter rib respectively.

The values of equivalent load of the middle rib for slabs $\left(4^{*} 10,6^{*} 10,8^{*} 10\right.$, $10 * 10$ and $12 * 10$ ) with thickness of $4 \mathrm{~cm}$ are $1.19,1.29,1.24,1.15$ and 1.09 the values of equivalent load of the quarter rib respectively.

The values of equivalent load of the middle rib for slabs $(4 * 10,6 * 10,8 * 10,10 * 10$ and $12 * 10)$ with thickness of $16 \mathrm{~cm}$ are $1.04,1.02,1.11,1.14$ and 1.11 the values of equivalent load of the quarter rib respectively.

The comparison between the middle rib and edge rib at (thickness of slab of 4and $16 \mathrm{~cm}$ with constant rib depth) is as follows:-

The values of S.F of the middle rib for slabs $(4 * 10,6 * 10,8 * 10,10 * 10$ and $12 * 10)$ with thickness of $4 \mathrm{~cm}$ are $2.25,1.81,1.92,2.11$ and 2.24 the values of S.F of the edge rib respectively

The values of S.F of the middle rib for slabs $(4 * 10,6 * 10,8 * 10,10 * 10$ and $12 * 10)$ with thickness of $16 \mathrm{~cm}$ are $1.1,1.07,1.06,1.11$ and 1.05 the values of S.F of the edge rib respectively.

The values of positive B.M of the middle rib for slabs $(4 * 10,6 * 10,8 * 10$, $10 * 10$ and $12 * 10$ ) with thickness of $4 \mathrm{~cm}$ are $1.45,1.58,1.93,2.11$ and 2.24 the values of B.M of the edge rib respectively.

The values of positive B.M of the middle rib for slabs $(4 * 10,6 * 10,8 * 10$, $10 * 10$ and $12 * 10$ ) with thickness of $16 \mathrm{~cm}$ are $1,1.02,1.13,1.18$ and 1.23 the values of B.M of the edge rib respectively.

The values of equivalent load of the middle rib for slabs $(4 * 10,6 * 10,8 * 10$, $10 * 10$ and $12 * 10$ ) with thickness of $4 \mathrm{~cm}$ are $2.4,1.97,2.72,3.2$ and 3.5 the values of equivalent load of the edge rib respectively.

The values of equivalent load of the middle rib with thickness of $16 \mathrm{~cm}$ for slabs $(4 * 10,6 * 10,8 * 10,10 * 10$ and $12 * 10)$ are $1.08,1.1,1.28,1.39$ and 1.43 the values of equivalent load of the edge rib respectively.

Comparison of the internal forces between the middle rib, the quarter rib and the edge rib with change the depth of rib is shown in Table 24.

Table 24

\begin{tabular}{|c|c|c|c|c|c|c|c|c|c|c|}
\hline \multicolumn{11}{|c|}{ comparing the internal force with changing depth of rib } \\
\hline \multirow{3}{*}{ forces } & \multirow{3}{*}{ SLAB } & \multicolumn{9}{|c|}{ rigidity of rib at thickness of slab $=5 \mathrm{~cm}$} \\
\hline & & \multicolumn{3}{|c|}{$\operatorname{tr}=15 \mathrm{~cm}$} & \multicolumn{3}{|c|}{$\operatorname{tr}=20 \mathrm{~cm}$} & \multicolumn{3}{|c|}{$\operatorname{tr}=25 \mathrm{~cm}$} \\
\hline & & $\begin{array}{l}\text { at the } \\
\text { edge }\end{array}$ & $\begin{array}{c}\text { in } \\
\text { qurter }\end{array}$ & $\begin{array}{c}\text { in } \\
\text { middle }\end{array}$ & $\begin{array}{l}\text { at the } \\
\text { edge }\end{array}$ & $\begin{array}{c}\text { in } \\
\text { qurter }\end{array}$ & $\begin{array}{c}\text { in } \\
\text { middle }\end{array}$ & $\begin{array}{l}\text { at the } \\
\text { edge }\end{array}$ & $\begin{array}{c}\text { in } \\
\text { qurter }\end{array}$ & $\begin{array}{c}\text { in } \\
\text { middle }\end{array}$ \\
\hline \multirow{3}{*}{$\begin{array}{l}\text { S.F } \\
\text { B.M "1" } \\
\text { B.M "2" }\end{array}$} & \multirow{3}{*}{$4 * 10$} & 0.26 & 0.45 & 0.46 & 0.39 & 0.66 & 0.74 & 0.5 & 0.87 & 0.99 \\
\hline & & -0.07 & -0.24 & 0.29 & -0.06 & -0.36 & -0.46 & 0 & -0.45 & 0.6 \\
\hline & & 0.2 & 0.22 & 0.24 & 0.41 & 0.5 & 0.53 & 0.71 & 0.85 & 0.92 \\
\hline \multirow{3}{*}{$\begin{array}{l}\text { S.F } \\
\text { B.M "1" } \\
\text { B.M "2" }\end{array}$} & \multirow{3}{*}{$6 * 10$} & 0.5 & 0.76 & 0.97 & 0.7 & 1.04 & 1.3 & 0.9 & 1.27 & 1.54 \\
\hline & & -0.3 & -0.56 & -0.79 & -0.37 & -0.77 & -1.11 & -0.35 & -0.85 & -1.25 \\
\hline & & 0.44 & 0.57 & 0.7 & 0.84 & 1.07 & 1.28 & 1.3 & 1.6 & 1.89 \\
\hline \multirow{3}{*}{$\begin{array}{l}\text { S.F } \\
\text { B.M "1" } \\
\text { B.M "2" }\end{array}$} & \multirow{3}{*}{$8 * 10$} & 0.41 & 1 & 1.28 & 0.62 & 1.29 & 1.57 & 0.85 & 1.5 & 1.73 \\
\hline & & -0.19 & -0.82 & -1.17 & -0.13 & -0.96 & -1.37 & 0 & -0.94 & -1.31 \\
\hline & & 0.57 & 0.96 & 1.24 & 1 & 1.57 & 1.95 & 1.48 & 2.17 & 2.55 \\
\hline \multirow{3}{*}{$\begin{array}{l}\text { S.F } \\
\text { B.M "1" } \\
\text { B.M "2" }\end{array}$} & \multirow{3}{*}{$10 * 10$} & 0.33 & 1.16 & 1.43 & 0.58 & 1.44 & 1.65 & 0.82 & 1.62 & 1.75 \\
\hline & & 0 & -0.94 & -1.3 & 0.1 & -1 & -1.29 & 0.23 & -0.9 & -1.05 \\
\hline & & 0.64 & 1.3 & 1.67 & 1.1 & 2 & 2.4 & 1.62 & 2.64 & 3 \\
\hline \multirow{3}{*}{$\begin{array}{l}\text { S.F } \\
\text { B.M "1" } \\
\text { B.M "2" }\end{array}$} & \multirow{3}{*}{$12^{*} 10$} & 0.3 & 1.13 & 1.48 & 0.55 & 1.54 & 1.66 & 0.8 & 1.7 & 1.76 \\
\hline & & 0.11 & -0.97 & -1.25 & 0.29 & -0.94 & -1.07 & 0.42 & -0.76 & -0.73 \\
\hline & & 0.69 & 1.6 & 2 & 1.2 & 2.37 & 2.76 & 1.74 & 3 & 3.33 \\
\hline
\end{tabular}


The comparison between the middle rib and quarter rib at (depth of rib 15 and $25 \mathrm{~cm}$ with constant slab thickness) is as follows:-

The values of S.F of the middle rib for slabs $(4 * 10,6 * 10,8 * 10,10 * 10$ and $12 * 10$ ) with depth of $15 \mathrm{~cm}$ of rib are $1.02,1.27,1.28,1.23$, and 1.3 the values of S.F of the quarter rib respectively

The values of S.F of the middle rib for slabs $(4 * 10,6 * 10,8 * 10,10 * 10$ and $12 * 10$ ) with depth of $25 \mathrm{~cm}$ of rib are $1.14,1.21,1.15,1.08$ and 1.03 the values of S.F of the quarter rib respectively

The values of positive B.M of the middle rib for slabs $\left(4 * 10,6 * 10,8^{*} 10\right.$, $10 * 10$ and $12 * 10$ ) with depth of $15 \mathrm{~cm}$ of rib are $1.09,1.23,1.29,1.28$ and 1.25 the values of positive B.M of the quarter rib respectively

The values of positive B.M of the middle rib for slabs $(4 * 10,6 * 10,8 * 10$, $10 * 10$ and $12 * 10$ ) with depth of $25 \mathrm{~cm}$ of rib are $1.08,1.18,1.17,1.14$ and 1.11 the values of positive B.M of the quarter rib respectively.

The values of equivalent load of the middle rib for slabs $(4 * 10,6 * 10,8 * 10$, $10 * 10$ and $12 * 10$ ) with depth of $15 \mathrm{~cm}$ of rib are $1.15,1.3,1.36,1.34$ and 1.26 the values of equivalent load of the quarter rib respectively.

The values of equivalent load of the middle rib for slabs $(4 * 10,6 * 10,8 * 10$, $10 * 10$ and $12 * 10$ ) with depth of $25 \mathrm{~cm}$ of rib are $1.14,1.29,1.25,1.14$ and 1.08 the values of equivalent load of the quarter rib respectively

The comparison between the middle rib and edge rib at (depth of rib 15 and 25 $\mathrm{cm}$ with constant slab thickness) is as follows:-

The values of S.F of the middle rib for slabs $\left(4 * 10,6 * 10,8^{*} 10,10^{*} 10\right.$ and $12 * 10$ ) with depth of $15 \mathrm{~cm}$ of rib are $1.76,1.94,3.12,4.33$, and 4.93 the values of S.F of the edge rib respectively

The values of S.F of the middle rib for slabs $(4 * 10,6 * 10,8 * 10,10 * 10$ and $12 * 10)$ with depth of $25 \mathrm{~cm}$ of rib are $1.98,1.71,2.03,2.13$ and 2.2 the values of S.F of the edge rib respectively.

The values of positive B.M of the middle rib for slabs $(4 * 10,6 * 10,8 * 10$, $10 * 10$ and $12 * 10$ ) with depth of $15 \mathrm{~cm}$ of rib are 1.2, 1.6, 2.17, 2.6 and 2.9 the values of positive B.M of the edge rib respectively.

The values of positive B.M of the middle rib for slabs $(4 * 10,6 * 10,8 * 10$, $10 * 10$ and $12 * 10$ ) with depth of $25 \mathrm{~cm}$ of rib are $1.29,1.45,1.72,1.85$ and 1.91 the values of positive B.M of the edge rib respectively

The values of equivalent load of the middle rib for slabs $(4 * 10,6 * 10,8 * 10$, $10 * 10$ and $12 * 10$ ) with depth of $15 \mathrm{~cm}$ of rib are 2, 2.01, 3.17, 4.6 and 5.6 the values of equivalent load of the edge rib respectively.

The values of equivalent load of the middle rib for slabs $(4 * 10,6 * 10,8 * 10$, $10 * 10$ and $12 * 10$ ) with depth of $25 \mathrm{~cm}$ of rib are $2.15,1.95,2.62,2.92$ and 3.06 the values of equivalent load of the edge rib respectively

The difference in the internal forces between the ribs may be due to: - each of rib rigidity and slab rigidity shared in resisting and transferring the loads. Most of transferred load by slab is distributed in the perpendicular direction on the ribs. Near to the edge, the rigidity of slab in the perpendicular direction on ribs is increasing due to its influencing to the solid part and edge beams. So near to the edge, the load portion on slab is increasing but decreasing on the ribs, and due to that, the internal forces in the middle rib are bigger than other ribs. 


\section{CONCLUSIONS}

From this study, the following conclusions can be deduced:

1. There was a great difference in the internal forces 'S.F and B.M' which are produced in the ribs by the two methods "traditional method" and "exact method".

2. A) The produced moment at the end of the rib by traditional method equals to zero for all slabs, while in fact, the real behavior is completely different concerning the internal forces on the rib. The connection between rib and supported beam is rigid and produces negative moments at the ends of the rib. These moments decrease the positive moment in middle of the rib and transfer to the beam as torsion moments. The negative moments must be considered in design.

B) With increasing the width of slab, the produced negative moments at the ends of the rib decrease.

3. The edge beams which are parallel to the ribs in the traditional method have no effect on the distribution of the loads or the internal forces produced in the rib. Where the traditional method assumed that the loads are transferred completely through the ribs to supported beams. The effect of edge beams was investigated in this study, where it was found :-

A) The existence of edge beams decreases the negative and positive B.M for all studied slabs.

B) The case of slab without edge beam was completely similar using the traditional method or exact method where the role of slab in this case in transferring the loads is negligible and the loads are transferred through ribs only.

C) The edge beams causes the difference of the B.M.D for the edge ribs than the produced B.M in the middle rib. While it was in case of slab without edge beam almost constant compared with the produced B.M in the middle rib for all studied slabs.

4. The effect of the existence of solid parts on decreasing the bending moments produced in the ribs

5. A) The Egyptian code recommends using cross ribs "one to three ribs " in one way ribbed slab when the length of these slabs are greater than $5 \mathrm{~m}$ to decrease the deflection of slab. The code doesn't take into account the effect of cross ribs on the structural behavior of the ribs and the internal forces which produced in the cross ribs. This study showed that using cross ribs, the B.M produced in the main ribs for slabs was decreased compared with those without cross ribs.

B) The produced B.M in the cross ribs was great compared with the main ribs and must be taken into consideration.

6. A) In the traditional method, the load completely transfers from the slab surface to the ribs regardless the change in slab thickness. This study showed the effect of slab thickness on the internal forces in the ribs where different slabs were studied with thicknesses of $(4,5,8,12$ and 16) $\mathrm{cm}$ and it was found :-With increasing the thickness of slab, the produced shear force and bending moments in the rib decrease. So the maximum values of S.F and B.M were at thickness of $4 \mathrm{~cm}$ of slab, then decrease until reach to the minimum values at thickness of $16 \mathrm{~cm}$ of slab.

B) The produced B.M at the connection between rib and solid part changes with the change of slab thickness. The value of this moment was negative for slabs with 
thickness of $4 \mathrm{~cm}$ then decreased with increasing the thickness until reached to zero or positive value for slabs with thickness of $16 \mathrm{~cm}$.

7. Increasing the depth of the rib $(15,20$ and 25$) \mathrm{cm}$ increase the produced shear force and bending moment in the rib.

8. The produced shear force and bending moments in the rib increase with increasing the width of one way slabs.

9. A) The produced shear force and bending moments in the rib in short direction "a" increase with increasing the width of two way slabs. While the maximum value of equivalent load was at width $6 \mathrm{~m}$ and the minimum value was at width of slab of $10 \mathrm{~m}$.

B) The produced shear force and bending moments in the rib for two way slabs in long direction " $\mathrm{b}$ " increase as the width of slab increases. Also the minimum value of equivalent load was at width of $6 \mathrm{~m}$ of slab and the maximum value of equivalent load was at width of slab of $10 \mathrm{~m}$.

10. In two way slabs, the coefficients $(\alpha)$ and $(\beta)$ don't depend only on the dimensions of slab, but also depend on the thickness of slab and the depth of rib.

11. A) The internal forces decrease as the location of rib is near to the edge of slab. So the produced S.F and B.M in the middle rib were bigger than S.F and B.M in other ribs. The difference in the internal forces between the ribs decreases as the slab thickness increases. Also, with increasing the depth of rib, the S.F and B.M increase until reach to maximum values at depth of $25 \mathrm{~cm}$. While in the traditional method, loads transfer uniformly through the ribs.

B) The behavior of the quarter rib and edge rib had the same trend as the rib in the mid of the slab. So the S.F and B.M of the rib were maximum values at thickness of $4 \mathrm{~cm}$ of slab, and then decrease until reach to the minimum values at thickness of $16 \mathrm{~cm}$ of slab. Also, with increasing the depth of rib, the S.F and B.M increase until reach to maximum values at depth of $25 \mathrm{~cm}$.

\section{REFERENCES}

1. ACI committee 318, 'Building Code Requirements for reinforced concrete (ACI 318-95) and Commentary (ACI 318-89) ', American concrete Institute, Detroit. (1995)

2. BS 8110-97, , 'Structural use of concrete', British Standard Institution, London (1997)

3. Bobrowski, J., 'The future and selection of structural form', The structure Engineer, V59A, NO.2 ,PP., 43-48 (Feb 1981)

4. ECP 203 'Egyptian Code for Design and Construction of reinforced Concrete Structures, 2007'

5. Cope, R.j., and Clark, L.A, , 'Concrete slabs: analysis and design', Elsevier applied science publishers, London and New York, 502 pp, (1984).

6. Hilal, M. 'Fundamentals of Reinforced And Prestressed Concrete', Vol 1, Cairo, 1987.

7. Khalil, I. W., 'Design of Reinforced concrete slabs' (1988) 
8. Michel Bakoum, 'Structural Mechnics' Vol.II Cairo 1992.

\section{التحليل الإنشائي للبلاطات ذات الأعصاب}

يتم التحليل التقليدي للبلاطات ذات الأعصاب في كثير من كودات التصميم منل الكود المصري والكود الامريكى والكود البريطاني طبقا لقواعد التصميم للبلاطات المصمتة أو البلاطات المسطحة. هذه الطرق "التقليدية" لا تأخذ في الاعتبار الكثير من العوامل التي تؤثر على قيم القوي الداخلية المتولدة في الأعصاب منل سمك البلاطة أو عمق العصب. لذا كانت الحاجة إلى طريقه أخرى نأخذ في الاعتبار العوامل المهملة في الطريقة التقليدية. فقد ثم تحليل البلاطات ذات الأعصاب في هذه الدراسة كوحدة واحده عن طريق نظرية العناصر الدقيقة باستخدام برنامجٍ SAP2000 في البعدين x,y والتي أوضحت وجود فروق كبيره في القوى الداخلية المتولدة من عزوم انحناء وقوى قاصه بينها وبين الطريقة التقليدية . أيضا شملت هذه الدراسة العوامل التي لم تؤخذ في الاعتبار في الطريقة التقليدية وهى الاتصال بين العصب والكمرات الساندة، نأثير وجود الأجزاء الصلبة العمودية على الأعصاب والموازية لله،الكمرات الطرفية الموازية للأعصاب وتأثنرها على القوى الداخلية،الأعصاب الداعمة للبلاطات ذات الاتجاه الواحد في حالة زيادة بحورها وتأثيرها على سلوك الأعصاب الرئيسية ، تأثثر تغير سمك البلاطة، تغير عمق العصب ، تغير عرض البلاطات، تأثير تغير موقع العصب واقترابه من حافة البلاطة. وقد بينت الدراسة مدى تأثير هذه العوامل على قيم القوى الداخلية المتولدة في الأعصاب وضرورة أخذها في الاعتبار عند التحليل.هذه الدراسة اشتنمت على تحليل البلاطات ذات الأعصاب في الاتجاه الواحد وفى الاتجاهين في السلوك المرن للمادة. 